\title{
Does Immigration Affect the Phillips Curve? Some Evidence for Spain*
}

\author{
Samuel Bentolila \\ CEMFI
}

\author{
Juan J. Dolado \\ Universidad Carlos III
}

\author{
Juan F. Jimeno \\ Banco de España
}

June 2008

\begin{abstract}
The Phillips curve has flattened in Spain over 1995-2006: unemployment has fallen by 15 percentage points, with roughly constant inflation. This change has been much more pronounced than elsewhere. We argue that this stems from the immigration boom in Spain over this period. We show that the New Keynesian Phillips curve is shifted by immigration if natives' and immigrants' labor supply elasticities and bargaining power differ. Estimation of this curve for Spain indicates that the fall in unemployment since 1995 would have led to an annual increase in inflation of 2.5 percentage points if it had not been largely offset by immigration.
\end{abstract}

Keywords: Phillips curve, immigration

JEL Codes: E31, J64.

Forthcoming in the European Economic Review (2009)

*The first author is also affiliated with CEPR and CESifo; the second and third with CEPR and IZA. We are grateful to Javier Andrés, Olivier Blanchard, Alex Cukierman, Harris Dellas, Jordi Galí, Thorvaldur Gylfason (the Editor), Steve Nickell, an anonymous referee, and participants at the June 2007 Kiel Institute for the World Economy conference on "The Phillips Curve and the Natural Rate of Unemployment" and at seminars at Bank of Israel, Bank of Spain, INSIDE (IAE/CSIC), MadMac, Swiss National Bank, University of Bern, and University of Oslo for helpful comments. The first two authors gratefully acknowledge financial support from Ministerio de Educación y Ciencia (ConsoliderIngenio 2010). Corresponding author: Samuel Bentolila, CEMFI, Casado del Alisal 5, 28014 Madrid, e-mail: bentolila@cemfi.es, Tel. +34914290551, Fax. +34914291056. 


\section{Introduction}

Over the period 1995-2006, Spanish unemployment has decreased by almost 15 percentage points, from $22 \%$ to $8 \%$, while inflation has remained subdued, falling first from $4 \%$ to $2 \%$ in the run-up to European Monetary Union (EMU) and then moving back again to 3-4\% since the 2000s. Thus, as depicted in Figure 1, there have been remarkable changes in the position and slope of the Spanish Phillips curve (henceforth, PC), which has shifted inwards and become much flatter. These trends have been shared by many other countries over that period. For instance, the fall in the inflation rate and its volatility in Spain is very similar to those in the Euro area. ${ }^{1}$ Spain is however atypical in that the favorable inflation developments have coincided with a fall in unemployment which is much larger than the average 2.5 percentage-point drop in the Euro area.

The causes of the reduction in Spanish unemployment since the mid-1990s have been analyzed to some extent elsewhere (see, e.g., Bentolila and Jimeno, 2006). However, the changes in the long-run level of inflation and its short-run tradeoff with unemployment remain largely unexplored. Most of the standard stories proposed to explain the recent joint evolution of inflation and unemployment in other countries do not seem very useful in the case of Spain. For instance, while structural unemployment has clearly fallen, it is difficult to identify key labor market reforms that could explain such a large reduction and hence sustain a lower level of long-run inflation at current unemployment rates. Next, a rise in the productivity growth rate, which has been proposed to explain the improved inflation-unemployment tradeoff in the United States (Ball and Moffitt, 2001), does not fit the Spanish experience either. Indeed, over the last decade, productivity growth in Spain has, if anything, fallen, being among the lowest in the European Union nowadays. Likewise, explanations based on the effects of monetary policy on real activity (Karanassou et al., 2002, and Karanassou and Snower, 2007) require extreme assumptions leading to the existence of a non-vertical PC in the long run. It has also been argued that the opening of both the trade and the capital accounts lead to a flat-

\footnotetext{
${ }^{1}$ The decline in inflation volatility has happened in many other economies, alongside a decline in GDP volatility. This is often referred to as the "Great Moderation" (see Bernanke, 2004, for a survey).
} 
tening of the PC (Razin and Loungani, 2007), although other authors point out that if globalization increases competition and, hence, makes wages and prices more flexible, the PC ought to become steeper, not flatter. ${ }^{2}$ Moreover, despite the noticeable increase in trade openness since the early 1990s, it is doubtful that it could sustain low inflation on its own, in the face of such a large reduction in unemployment. Finally, EMU could have contributed to the flattening of the PC, as low inflation expectations became better anchored. Still, why inflation did not surge with such a dramatic reduction in unemployment is puzzling.

\section{FIGURE 1 ABOUT HERE}

Recent studies on the inflation rate and its tradeoff with unemployment in Spain have taken three different approaches. First, the sources of the Spanish persistent positive inflation differential vis-à-vis the rest of the Euro area have been analyzed within calibrated dynamic stochastic general equilibrium models. This type of studies concludes that the differential could be explained either by demand shocks biased towards non-tradable goods combined with real wage rigidities (López-Salido et al., 2005) or by fluctuations in productivity growth in the tradable sector (Rabanal, 2006). Secondly, there is research on the possibility of a non-zero unemployment-inflation tradeoff in the long-run Spanish PC, which focuses on the interaction between money growth and nominal frictions by estimating reduced-form inflation equations (Karanassou et al., 2002). Lastly, and closer to our work, Galí and López-Salido (2001) estimate a New Keynesian PC (NKPC) for the Spanish economy during the disinflation period (1980-1998). They show that the curve fits the data quite well, though with a relatively high degree of inflation persistence, and that the price of imported intermediate goods and labor market frictions are the key factors driving the dynamics of marginal costs, which determine inflation jointly with inflation expectations.

None of these studies, however, addresses a recent fundamental change affecting the Spanish labor market, namely the immigration boom that has taken place since the mid-1990s. The proportions of foreigners in the Spanish population and labor force were

\footnotetext{
${ }^{2}$ See Ball (2006). Further discussion is found in Rogoff (2003) and Bean (2006).
} 
both around $1 \%$ in 1995 , while in 2006 they were around $9 \%$ and $14 \%$, respectively. As we will discuss later, there have been very large waves of immigration, specially since 2000, coming mainly from Latin America, North Africa, and Eastern Europe.

In this paper we aim at filling this gap by analyzing the consequences of immigration for the joint behavior of unemployment and inflation. So far this topic has drawn little attention in the literature. To our knowledge, only two recent papers tackle it directly. On the one hand, Razin and Binyamini (2007) show that immigration and outmigration raise the elasticities of labor supply and labor demand, inducing a flatter PC. On the other hand, Engler (2007) finds a similar result via temporary outmigration of natives. Our approach differs from theirs in that we stress other labor-market channels through which immigration can affect inflation. To the extent that wages are differently determined for natives and immigrants -for instance if immigrants are less well represented by labor unions than natives- or insofar as the marginal rate of substitution between consumption and leisure is different for each group -immigrants tend to be more mobile and more willing to take low-paid jobs than natives- expected marginal costs can fall as immigration increases. If increased immigration reduces labor costs or the rate at which they rise, the effect of increased immigration on the position of the Phillips curve, as well as on aggregate supply, is similar to the effect of a fall in oil prices. Through these effects, we embed immigration into an otherwise standard NKPC with real wage sluggishness which, as Blanchard and Galí (2007) have argued, is a key feature in explaining the dynamic trade-offs between inflation and unemployment. In this way, we derive a microfounded inflation equation that is estimated and used to account for the impact of the immigration boom on the recent evolution of the Spanish PC. ${ }^{3}$

The rest of the paper is structured as follows. In Section 2 we review in more detail several hypotheses used in the literature to explain the changes in the PC in most major economies and discuss whether they fit the evidence for Spain. In Section 3 we document the changes in the Spanish labor market since the mid-1990s, focusing on immigration.

\footnotetext{
${ }^{3}$ We do not explore other channels through which immigration may affect prices. For instance, Lach (2007) finds that the large 1990 wave of immigrants to Israel reduced prices due to their higher price elasticities and lower search costs than the natives'.
} 
In Section 4 we derive an NKPC when the labor market is composed of two worker types, namely immigrants and natives. In Section 5 we discuss the results from estimating the NKPC with immigration for Spain since the early 1980s. Section 6 contains evidence about how our proposed NKPC performs at the industry level, given that immigration is highly concentrated in some industries. Section 7 concludes. Two Appendices gather some analytical derivations and a description of the data.

\section{The joint fall of inflation and unemployment}

The recent evolution of inflation and unemployment in Spain brings out three stylized features: a reduction in inflationary expectations, a large fall in the structural unemployment rate or NAIRU, and a flatter PC. While the fall in inflation expectations is clearly due to the change in the monetary policy regime in the late 1990s brought forth by EMU, the factors behind the other two changes are less evident.

According to some estimates, the NAIRU has fallen from about 15\% in 1996 to $9 \%$ in 2006 (Izquierdo and Regil, 2006). This is remarkable, as structural policy indicators do not exhibit important changes. For instance, the reform intensity indicator of Brandt et al. (2005) for 1994-2004 ranks Spain in the 24th position out of 30 OECD countries. In fact, considering all institutions usually regarded as relevant in explaining structural unemployment -tax wedge, employment protection legislation (EPL), unemployment benefits, wage setting and industrial relations, working-time flexibility, incentives for labor market participation, and product market regulation- Spain only shows noticeable changes in the strictness of EPL for permanent labor contracts (which has been significantly relaxed between 1994 and 2003 according to the OECD -probably a too benign judgment of a labor reform in 1997) and in product market regulation (an improvement shared by most other OECD countries). ${ }^{4}$

As for the unemployment-inflation tradeoff, it has been argued that higher productivity growth could reduce the level of inflation at given wages. The basic idea is that misalignment between wage aspirations and productivity shifts the $\mathrm{PC}$, and it has

\footnotetext{
${ }^{4}$ On labor market reforms in Spain see Dolado et al. (2002) and Bentolila and Jimeno (2006).
} 
been used to rationalize the inward shifts in the United States PC since 1995 (Ball and Moffitt, 2001). However, since the mid-1990s, when unemployment began to fall in Spain, the productivity growth rate has also fallen significantly: annual growth in labor productivity fell from $2.5 \%$ in $1981-1994$ to $0.4 \%$ in $1995-2006$, while total factor productivity (TFP) growth fell from $0.5 \%$ to $-0.6 \%$ over those periods (EU KLEMS Database, www.euklems.net.).

Lastly, another potential factor driving the fall in inflation is globalization, which operates through two basic mechanisms: increasing trade integration and global competition, and changing import prices (International Monetary Fund, 2006). As for the former, the degree of openness (exports plus imports divided by GDP) has indeed increased, but along a long-term trend. Thus, it is far from being a new phenomenon although it can be argued that its trend tilts up since 1992, coinciding with the onset of a disinflation episode (see Figure 2). Yet, in our view, the evolution of inflation during 1992-1998 is mostly determined, as in many other European countries, by the nominal convergence process required to join EMU. Secondly, Figure 3 shows that, although the growth rate of nominal imported input prices decelerated up to the early 1990s, with inflation following suit, since then it has fluctuated around a constant mean. This indicates a decoupling from inflation -which keeps declining until 1998. In our empirical model we will include imported input prices as a determinant of marginal costs and thus of inflation. In the next section we document another dimension of globalization, widely understood, which has changed more dramatically in Spain, namely immigration.

\section{FIGURES 2 AND 3 ABOUT HERE}

\section{The immigration boom}

In 1991 there were only about 350,000 foreigners living in Spain, but by 2006 the figure had risen to about 4.1 million, i.e. it went from $1 \%$ to $9.3 \%$ of total population. The average annual immigrant flow during 2000-2006 was around 485,000 persons, one of the largest among developed countries (cfr. 1 and 1.2 millions, respectively, in the European Union and the United States). This is quite a unique experience. Using comparable 
data from Eurostat, the Spanish yearly net immigration rate over 2000-2004 is equal to 1.3\% . No other large or middle-sized European country has sustained such a large inflow over a 5-year period since 1965 (when data start): the closest figures are $0.9 \%$ in Ireland over the same period and 1\% in Portugal over 1975-1979. ${ }^{5}$ The Spanish experience is comparable to the Israeli one, not in the surge in the immigration rate to $3.8 \%$ in 199091 , but rather in the steady flow of $1.2 \%$ per year over 1992-2000. Indeed, there have been clear inward shifts in the Israeli Phillips curve and some flattening post-1992. ${ }^{6}$

The geographical distribution of immigrants is roughly $24 \%$ from the European Union and $76 \%$ from the rest of the world (34\% from South America, 20\% from Africa, 13\% from Eastern Europe, $5 \%$ from Asia, and $4 \%$ from other areas). ${ }^{7}$ Immigrants are overrepresented, vis-à-vis natives, in agriculture (7.4\% vs. $5.6 \%$ in 2000-2006) and construction (17.8\% vs. $11.5 \%$ ), and they also show high shares in some service industries, like home services, and hotels and catering. For the most representative group of immigrants over the period 1996-2006, namely those aged 20-45 years old from Eastern Europe, Africa, and Latin America, Fernández and Ortega (2007) report that immigrants have slightly less schooling than natives (10.08 vs. 10.35 years, though those from Africa show a significantly lower figure, 7.5 years). Nevertheless, $39 \%$ of them take jobs for which they are overqualified, vis-à-vis $17 \%$ of the natives. ${ }^{8}$

As seen in Figure 4, immigration flows started to increase around 1996 and accelerated from 2000. Why did this happen precisely at that time? Mostly due to prosperity. The latest Spanish economic boom began in mid-1990s. More specifically the large fall in real interest rates during the process of adoption of the euro favored industries with large and long-lived investments, like construction, which are intensive in unskilled labor. This favorable demand shift took place precisely at a time when the cohorts of young unskilled native workers entering the labor market were rather small because, due to

\footnotetext{
${ }^{5}$ Countries like Cyprus, Luxembourg or Lichtenstein show similar or higher rates in certain periods.

${ }^{6}$ We are grateful to Saul Lach for providing the immigration data. For population, the source is Central Bureau of Statistics of Israel, www.cbs.gov.il.

${ }^{7}$ For a detailed account of recent immigration in Spain see Carrasco et al. (2008) and Dolado and Vázquez (2007).

${ }^{8} \mathrm{~A}$ worker is considered to be overeducated when his/her level of education is above the mean plus one standard deviation in his/her occupational category.
} 
low fertility, the Spanish population growth since the mid-1970s had stagnated. Thus, there was a large excesss demand for unskilled labor which fueled large immigration flows. As a result, Spain sustained high growth in the 2000s while many other European countries had low growth. Since 1995 Spanish GDP growth has surpassed the Euro area average by $1.3 \%$ per year while the differential in Spanish employment growth has been a staggering $2.9 \%$, implying that Spain has created $48 \%$ of all net new jobs in the Euro area (OECD Economic Outlook database, June 2007). Additionally, the progressive rise in female labor force participation also increased the demand for household services, ${ }^{9}$ which migrants were ready to provide at low wages. Finally, though there has not been an active policy of attracting immigrants, several amnesties granted legal residence to illegal immigrants (1996, 2000/2001, and 2005). These forces, alongside the crises in several Latin American countries in the early 2000s, the long-standing decline in Africa, and growing network effects provided strong pull and push effects on immigration.

\section{FIGURE 4 ABOUT HERE}

It is also worth stressing that in the 2000s the unemployment rate of immigrants has diverged from the national average, remaining well above that of natives (see Figure 5). The main reason is the sheer size of the inflows. Fernández and Ortega (2007) examine the labor market assimilation of immigrant workers in Spain, concluding that they tend to achieve similar unemployment rates as natives about five years after arrival. Thus, a continuous yearly influx of more than $1 \%$ of the labor force was bound to mechanically increase the average unemployment rate of immigrants. Moreover, even after their assimilation period, immigrants tend to be over-represented in temporary jobs, and in construction and certain service industries, all of which are associated with high turnover rates. ${ }^{10}$ This means that, even if their labor supply elasticity is lower than that of natives (as assumed in Section 4 below), we expect migrants to experience higher frictional unemployment than natives. As a first-pass indication of the potential impact

\footnotetext{
${ }^{9}$ The participation rate of native females aged $24-54$ rose from $57.5 \%$ in 1996 to $67.8 \%$ in 2004 .

${ }^{10}$ Fernández and Ortega (2007) report that over 1996-2006 the proportion of employed immigrants with temporary jobs was $60.7 \%$ (versus $33.6 \%$ for natives). They also show that immigrants have higher unemployment rates than natives after controlling for personal characteristics.
} 
of immigration on the Spanish labor market, note that there is a negative correlation between real wage growth and the differential between the immigrant and the overall unemployment rate. While over 1981-1995 average annual real wage growth was equal to $1.1 \%$, over $1996-2006$ it was equal to $-0.6 \%$.

\section{FIGURE 5 ABOUT HERE}

Immigrants are likely to have lower bargaining power vis-à-vis employers than natives. Apart from assimilation handicaps (e.g. in their command of the language), they often work in industries with lower coverage of collective wage bargaining. ${ }^{11}$ Their coverage rate is about 8 points lower than for natives, and the coefficient of correlation across industries between coverage and the immigrant share of employees is equal to -0.11 .

There is a long literature on the effects of immigration on the receiving country's labor market. Most studies analyze the impact on employment rates and wages of native workers. $^{12}$ Much less attention has been paid to immigration in the macroeconomic analysis of the labor market and, specifically, to its impact on the NAIRU and the unemployment-inflation tradeoff. This neglect is probably due to the property of longrun neutrality of labor supply in standard macroeconomic models of unemployment. However, assuming some differences between immigrants and natives, there are several channels through which immigration may affect labor market outcomes. First, there is an ongoing debate on whether immigrant and native workers are complements or substitutes in production (Ottaviano and Peri, 2006, and Borjas, 2003, respectively). Secondly, the employment patterns of immigrants and, in particular, their industry composition and geographical mobility suggest that they have different preferences regarding consumption and leisure than natives. For instance, as mentioned earlier, Razin and Binyamini (2007) show that immigration alters the elasticities of labor supply and labor demand, inducing a flatter PC. Lastly, it is likely that immigrants have a lower bargaining power than natives in noncompetitive labor markets. Hence, a rise in the immigration flow increases the labor intensity of production, changes the elasticity of labor supply, and decreases

\footnotetext{
${ }^{11}$ The degree of unionization is not available and, moreover, it does not mean much in the Spanish economy, since collective bargains are extended to all employees in the industry.

${ }^{12}$ See Card (2001) for the US, Carrasco et al. (2008) for Spain, and Borjas (1999) for a survey.
} 
the markup of wages over the marginal rate of substitution between consumption and leisure. In the next section, we explicitly model how these three effects interact to change the PC.

\section{An NKPC accounting for immigration}

In this section we extend the standard analysis of the NKPC to take into account heterogeneity across two types of workers with different characteristics, namely immigrants and natives. We first present the setup of the model and then solve for equilibrium with real wage rigidity and monopoly power.

\subsection{Model setup}

As is standard in the literature on the NKPC, we start by assuming an economy with a continuum of monopolistically competitive firms, each producing a differentiated product $(Q)$ and facing an isoelastic demand with price elasticity $\epsilon>1$. The production function is constant returns to scale (CRS) Cobb-Douglas with two inputs, labor $(N)$ and raw materials $(M)$. For simplicity, as in Blanchard and Galí (2007) (hereafter BG), we ignore capital in the following analysis, so that $Q$ should be interpreted stricto sensu as final output net of capital compensation. The main novelty here is the assumption that the labor input consists of two components, to be interpreted as native $\left(N_{1}\right)$ and immigrant workers $\left(N_{2}\right)$. Since both types of workers are bound to be imperfect substitutes, we aggregate them into the single labor-input index $(N)$ through a CES function. Hence,

$$
\begin{gathered}
Q_{t}=N_{t}^{1-\alpha} M_{t}^{\alpha} \\
N_{t}^{\rho}=\delta_{1} N_{1 t}^{\rho}+\delta_{2} N_{2 t}^{\rho},
\end{gathered}
$$

so that $\sigma=(1-\rho)^{-1}$ is the elasticity of substitution between native and immigrant workers. ${ }^{13}$

\footnotetext{
${ }^{13}$ The assumption of constant returns to scale in (1) can be relaxed to short-run decreasing returns $\left(\alpha_{m}+\alpha_{n}<1\right)$, considering that we ignore capital. BG discuss this case and show that the specification of the NKPC only differs from that derived below in (27), with $\alpha_{m}+\alpha_{n}=1$, in having the differenced unemployment rate as an additional regressor. This is checked in the empirical estimation below.
} 
By means of the envelope theorem, marginal costs plus the markup can be expressed as a function of the labor index as follows (hereafter lowercase letters denote logs of variables in levels):

$$
m c_{Q}+\mu^{p}=\omega-(q-n)-\ln (1-\alpha)+\mu^{p}
$$

where $\omega$ is the average real wage (i.e. the log of the nominal wage, $w$, minus the log of the gross output deflator, $\left.p_{Q}\right), m c_{Q}$ is the real marginal cost of producing $Q$, and $\mu^{p}$ $(=\log (\epsilon / \epsilon-1))$ is a constant price markup.

We assume that immigrant and native workers are not only different in production but also in their marginal rate of substitution between consumption and leisure (MRS), as given by the following functions, for $i=1,2$,

$$
U_{i}=\ln C_{i}-e^{\xi} \frac{N_{i}^{1+\phi_{i}}}{1+\phi_{i}},
$$

where $C_{i}$ is composite consumption (with elasticity of substitution equal to $\epsilon$ ) and $\xi$ is a preference parameter. Hence, the marginal rate of substitution, mrs, between consumption and labor is given by

$$
m r s_{i}=c_{i}+\phi_{i} n_{i}+\xi
$$

Following the discussion in Section 3, it is assumed that the slopes of the labor supply curves of immigrant and native workers in the wage-employment space differ. In particular, we proceed in the sequel as if $\phi_{2}>\phi_{1}$. Since the $\phi_{i}$ are the inverses of the respective Frisch elasticities of labor supply, this means that the labor supply of immigrants is taken to be less elastic than that of natives. ${ }^{14}$ This assumption will be tested in the empirical section below.

Then, taking a log-approximation of equation (2) around the steady-state, we can show that average employment and wages, in deviations from steady state, are given by

\footnotetext{
${ }^{14}$ This implies that, in the presence of a negative demand shock leading to a positive unemployment gap (i.e. $u_{2}-u>0$ ), immigrants are more ready to reduce their wages than natives in order to remain employed. By the same token, if a positive demand shock takes place, immigrants' wages would increase by a larger amount, given our linearity assumption. In order to check whether the labor supply curve of immigrant workers is concave, we will allow for a quadratic term in their relative unemployment when estimating the NKPC equation (27) below.
} 
(see Appendix A.1)

$$
\begin{aligned}
n & =\bar{\lambda} n_{1}+(1-\bar{\lambda}) n_{2} \\
\omega & =\bar{\lambda} \omega_{1}+(1-\bar{\lambda}) \omega_{2},
\end{aligned}
$$

with $\left.\bar{\lambda} \simeq \delta_{1}\left(\frac{\bar{N}_{1}}{\bar{N}}\right)^{\rho}=1-\delta_{2} \overline{(I R}\right)^{\rho}$, where $\overline{I R}\left(=\bar{N}_{2} / \bar{N}\right)$ denotes the steady-state immigration rate defined in terms of employment.

The expressions in (5) would hold exactly if we had assumed a Cobb-Douglas labor aggregator in equation (2), which is the limit case of the CES function when $\sigma$ tends to 1. In that case, $\bar{\lambda}$ and $1-\bar{\lambda}$ could be interpreted as the distribution parameters $\delta_{1}$ and $\delta_{2}$, respectively. However, the Cobb-Douglas specification poses at least two problems. First, it implies that production cannot be carried out without immigrants, which does not sit well with the very low fraction of employment represented by immigrants at the beginning of our sample period (0.3\%). And secondly, the immigration rate has increased steadily over time, which renders its steady-state value $\overline{I R}$ a not well-defined concept. We could tackle this issue by endogeneizing $\overline{I R}$ in terms of a Harris-Todaro non-arbitrage wage condition, so that $\overline{I R}$ would be implicitly defined by the equality of expected wages of immigrants in the countries of origin and destination (see Razin and Binyamini, 2007). However, this route is not viable since at the estimation stage we would need long time series of immigrants' wages in all origin countries, which are unavailable. Another possibility would be to adopt the standard approach advocated by Galí and Gertler (1999) of using the labor income share to capture the evolution of the real marginal cost. Given our CES specification in (2), this would imply that the real marginal cost would be equal to a linear combination of the labor income share and the relative wage of native and immigrant workers. ${ }^{15}$ Unfortunately, this route is again not feasible, since there is no data on wages according to worker nationality for Spain.

Given these caveats, we need to account for time variation in the weighting factors used to aggregate employment and wages of the two types of workers in (5). To do so, we take a shortcut by implementing a similar approximation to the one before,

\footnotetext{
${ }^{15}$ This is akin to the procedure developed by Rotemberg and Woodford (1999) for a CES production function, instead of (1), with labor and raw materials as inputs. They show that, besides the labor share, the other determinant of real marginal cost is the relative price of the two inputs.
} 
but this time around the observed values of the ratio $N_{2} / N$ during our sample, rather than around its steady-state value, $\bar{N}_{2} / \bar{N}$. This yields a time-varying parameter given by $\lambda(I R)=1-\delta_{2}(I R)^{\rho}$, where $I R$ is the observed immigration rate in terms of employment. Next, we approximate $\lambda(I R)$ (hereafter, $\lambda$ for short) by a quadratic function in terms of the (logged) employment-based immigration rate ir $\left(=n_{2}-n\right)$, which arises from using a second-order Taylor approximation of $\lambda$ around the Cobb-Douglas case of $\rho=0 .{ }^{16}$ In this way, the time variation in $\lambda$ around $\bar{\lambda}$ is captured by changes in $i r$ over the sample period. As shown in Appendix A.2, this Taylor expansion takes the form

$$
\lambda \simeq \bar{\lambda}-(1-\bar{\lambda})\left(\rho i r+\frac{\rho^{2}}{2} i r^{2}\right)
$$

i.e., an expression which will give rise to interaction terms between one of the explanatory variables and the two terms in $i r$ when we reach the final specification of the NKPC (see Section 4.5 below). Hence, in the sequel, we will proceed by replacing (5) with the alternative approximations (where $\lambda$ is defined as in (6)):

$$
\begin{aligned}
& n=\lambda n_{1}+(1-\lambda) n_{2} \\
& \omega=\lambda \omega_{1}+(1-\lambda) \omega_{2} .
\end{aligned}
$$

\subsubsection{Sluggish wages and markups}

As in BG, we consider the case where real wages respond sluggishly to labor market conditions, due to some (unmodeled) imperfection in the labor market. Further, it is assumed that there are gross wage markups (possibly time varying), denoted (in logs) by $\mu_{i}^{\omega}(i=1,2)$. The markups reflect factors like any monopoly power held by workers in the labor market or distortionary taxes on labor income, which can differ across worker types. Specifically, it is assumed that real wages of both native and immigrant workers follow a partial adjustment model of the form (again for $i=1,2$ ):

$$
\omega_{i}=\gamma \omega_{i,-1}+(1-\gamma)\left(m r s_{i}+\mu_{i}^{\omega}\right)
$$

Thus, substituting (4) in (8) yields

$$
\omega_{i}=\gamma \omega_{i,-1}+(1-\gamma)\left(c_{i}+\phi_{i} n_{i}+\xi+\mu_{i}^{\omega}\right)
$$

\footnotetext{
${ }^{16}$ This resembles the procedure advocated by Kmenta (1967) to estimate CES production functions.
} 
where $\gamma \in[0,1)$ is the sluggishness parameter. ${ }^{17}$ In order to compute the average wage $\omega$, using (7), it is useful to notice the following result regarding the weighted sum of the $n_{i}$ terms appearing in the aggregation of the two wages in (9),

$$
\lambda \phi_{1} n_{1}+(1-\lambda) \phi_{2} n_{2}=\psi n+\phi_{21} i r
$$

where $\psi=\lambda \phi_{1}+(1-\lambda) \phi_{2}$, i.e. the average of the inverse labor supply elasticities, and $\phi_{21}=(1-\lambda)\left(\phi_{2}-\phi_{1}\right)>0$. Then, denoting the lag operator by $L$ and noting that the partial adjustment equations (8) can be rewritten as $\omega_{i}=\frac{(1-\gamma)\left(m r s_{i}+\mu_{i}^{\omega}\right)}{1-\gamma L}=$ $m r s_{i}+\mu_{i}^{\omega}-\frac{\gamma \Delta\left(m r s_{i}+\mu_{i}^{\omega}\right)}{1-\gamma L}$, the combination of (4) and (9), yields the average wage

$$
\omega=q+\psi n+\phi_{21} i r+\xi+\mu^{\omega}-\frac{\gamma \Delta\left(q+\psi n+\phi_{21} i r+\xi+\mu^{\omega}\right)}{1-\gamma L}
$$

where, in our economy with just consumption goods, average consumption is equal to output, that is, $q=\lambda c_{1}+(1-\lambda) c_{2}$, and $\mu^{\omega}=\lambda \mu_{1}^{\omega}+(1-\lambda) \mu_{2}^{\omega}$ is the average markup.

From (1), the MRS between labor and raw materials implies that labor productivity behaves as

$$
q-n=\alpha(m-n)=\alpha\left(\omega-s_{Q}\right)+\alpha \ln \frac{\alpha}{1-\alpha},
$$

where $s_{Q}$ is the real price of raw materials (i.e., the log of its nominal price, $p_{m}$, minus $\left.p_{Q}\right)$. Thereby, substituting this expression into (11), yields an equation describing the dynamic evolution of real wages from the workers' side:

$$
\omega=\Gamma \omega_{-1}+\frac{1-\Gamma}{1-\alpha}\left[\alpha \ln \frac{\alpha}{1-\alpha}+(1+\psi) n+\phi_{21} i r+\xi-\alpha s_{Q}+\mu^{\omega}\right],
$$

with $\Gamma=\frac{\gamma}{1-\alpha+\gamma \alpha}<1$.

\footnotetext{
${ }^{17}$ We also tried an alternative specification in which the persistence parameters differ across workers whereas their preferences are identical, i.e.,

$$
\omega_{i}=\gamma_{i} \omega_{i,-1}+\left(1-\gamma_{i}\right)\left(m r s+\mu^{\omega}\right) ; i=1,2 .
$$

When using the aggregation procedure in (6), this yields the following model for wages

$$
\begin{aligned}
\omega-\left(\gamma_{1}+\gamma_{2}\right) \omega_{-1}+\gamma_{1} \gamma_{2} \omega_{-2}= & \left(1-\gamma_{1}\right)\left(1-\gamma_{2}\right)\left(m r s+\mu^{\omega}\right)+ \\
& {\left[\lambda\left(\gamma_{2}-\gamma_{1}\right)+\gamma_{1}\left(1-\gamma_{2}\right)\right] \Delta\left(m r s+\mu^{\omega}\right) . }
\end{aligned}
$$

This leads to more complicated dynamics in the evolution of the real marginal cost and in the NKPC, which were rejected by our data. Hence, we opted for the model described in the text.
} 


\subsection{First-best equilibrium}

The next step is to derive the first-best price equilibrium in this economy. This corresponds to the case where prices and wages are flexible $(\gamma=0)$, and labor and goods markets are perfectly competitive, i.e. $\mu^{\omega}=\mu^{p}=0$. In such an equilibrium, from the firms' side, the real aggregate wage would be equal to the marginal product of labor (mpn), that is, $\omega=m p n=q-n+\ln (1-\alpha)$. Similarly, from the workers' side, the real wage would be equal to the marginal rate of substitution, that is, $\omega=q+\psi n+\phi_{21} i r+\xi$. Therefore, equating both expressions and labeling the first-best equilibrium value of a generic variable $x$ by $\bar{x}^{F}$, we find the following equilibrium condition relating the employment of natives and immigrants:

$$
(1+\psi) \bar{n}^{F}+\phi_{21} \overline{i r}^{F}=\ln (1-\alpha)-\xi
$$

\subsection{Equilibrium with real wage rigidities and monopoly power}

Going back to our economy with labor market frictions and monopolistic power in goods and labor markets, substitution of (13) into (12) yields the evolution of wage-setting from the workers' side,

$$
\omega=\Gamma \omega_{-1}+\frac{1-\Gamma}{1-\alpha}\left[\alpha \ln \alpha+(1-\alpha) \ln (1-\alpha)-\alpha s_{Q}+\mu^{\omega}+(1+\psi) \widetilde{n}+\phi_{21} \tilde{i r}\right],
$$

where $\widetilde{n}\left(=n-\bar{n}^{F}\right)$ and $\widetilde{i r}\left(=i r-\overline{i r}^{F}\right)$ are the deviations of $n$ and $i r$ from their corresponding first-best equilibrium values.

From the firms' side we have that $m c_{Q}+\mu^{p}=\omega-m p n+\mu^{p}$. Then, inserting (14) into this expression and using (1) yields the following equation describing the corresponding dynamic evolution of the real marginal cost of gross output

$$
(1-\Gamma L)\left(m c_{Q}+\mu^{p}\right)=\frac{(1-\Gamma)(1+\psi)}{1-\alpha} \widetilde{q}+(1-\Gamma) \phi_{21} \widetilde{i r}+\alpha \Gamma \Delta s_{Q}+(1-\Gamma)\left(\mu^{\omega}+\mu^{p}\right),
$$

where $\widetilde{q}=q-\bar{q}^{F}$.

\subsection{Unemployment and immigration in the marginal cost}

In order to express (15) in terms of observables, namely the unemployment $(u)$ and immigration rates, we follow BG in assuming that the (logged) labor supplies $\left(\ell_{i}\right)$ and 
the relative labor supply of immigrants vis-à-vis natives $\left(i r l=\ell_{2}-\ell_{1}\right)$ are implicitly defined by:

$$
\omega=q+\psi \ell+\phi_{21} i r l+\xi+\bar{\mu}^{\omega} .
$$

That is, $\ell$ and $i r l$ measure the notional quantities of labor that native and immigrant workers would like to supply given their current wage, marginal utility of income, and steady-state wage markup, $\bar{\mu}^{\omega}$. Hence, from the firms' side, substitution of (16) into (3), yields

$$
m c_{Q}+\mu^{p}=(1+\psi) \ell-(\ell-n)+\xi-\ln (1-\alpha)+\phi_{21} i r l+\bar{\mu}^{\omega}+\mu^{p} .
$$

Next, making use of the standard approximation $u \simeq \ell-n$, noticing that $i r l=$ $\left(i r l-\overline{i r}^{F}\right)+\overline{i r}^{F}$, and recalling the first-best equilibrium condition (13), we find that (17) can be rewritten as

$$
m c_{Q}+\mu^{p}=\frac{1+\psi}{1-\alpha} \widetilde{q}+\psi u+\phi_{21}\left(i r l-\overline{i r}^{F}\right)+\bar{\mu}^{\omega}+\mu^{p}
$$

Hence, solving for $(1+\psi) \widetilde{q} /(1-\alpha)$ in (18) and replacing it in (15), yields the following equation describing the evolution of $m c_{Q}+\mu^{p}$ in terms of observables

$$
\Delta\left(m c_{Q}+\mu^{p}\right)=-\frac{1-\Gamma}{\Gamma}\left[\psi u+\phi_{21}\left(u_{2}-u\right)-\widehat{\mu}^{\omega}\right]+\alpha \Delta s_{Q},
$$

where $\widehat{\mu}^{w}=\mu^{\omega}-\bar{\mu}^{\omega}$, and we have used the result that irl $-i r=\left(\ell_{2}-\ell\right)-\left(n_{2}-n\right) \simeq u_{2}-u$, i.e. the difference between the unemployment rate of immigrants and the aggregate unemployment rate.

\subsubsection{Interaction terms with immigration}

The next step is to notice that parameters $\psi$ and $\phi_{21}$ depend on the time-varying weight $\lambda$ in (6). Thus we need to express equation (19) in terms of constant parameters. To do so, notice that, since $\psi=\phi_{1}+(1-\lambda)\left(\phi_{2}-\phi_{1}\right)=\phi_{1}+\phi_{21}$, the linear combination of unemployment rates given by $\psi u+\phi_{21}\left(u_{2}-u\right)$ in (19) can be rewritten as follows (see Appendix A.2)

$$
\psi u+\phi_{21}\left(u_{2}-u\right)=\bar{\psi} u+\bar{\phi}_{21}\left(u_{2}-u\right)+\rho \bar{\phi}_{21} u_{2} i r+\frac{\rho^{2}}{2} \bar{\phi}_{21} u_{2} i r^{2}
$$


where $\bar{\psi}=\phi_{1}+\bar{\phi}_{21}$ and $\bar{\phi}_{21}=(1-\bar{\lambda})\left(\phi_{2}-\phi_{1}\right)$, with $\bar{\lambda}$ interpreted as in (5). Substitution of (20) into (19) yields an alternative specification of (19) in terms of constant rather than changing parameters, in which two new interaction terms of $u_{2}$ with $i r$ and $i r^{2}$ appear, namely

$$
\Delta\left(m c_{Q}+\mu^{p}\right)=-\frac{1-\Gamma}{\Gamma}\left[\bar{\psi} u+\bar{\phi}_{21}\left(u_{2}-u\right)+\rho \bar{\phi}_{21} u_{2} i r+\frac{\rho^{2}}{2} \bar{\phi}_{21} u_{2} i r^{2}-\widehat{\mu}^{\omega}\right]+\alpha \Delta s_{Q} .
$$

Finally, deviations of the wage markup from its steady-state value, i.e. $\widehat{\mu}^{w} \neq 0$, would also alter the marginal cost (see Galí et al., 2001). As explained in Appendix A.3, in a right-to-manage model of wage determination by firms and unions, among other alternatives, a labor supply shift due to immigration can be captured by a rise in $u_{2}-u$ -since it is likely that immigrants will take longer than natives in finding a job- which, in turn, could be interpreted as implying a fall in $\widehat{\mu}^{w}$. For simplicity, we assume a linear relationship of the form $\widehat{\mu}^{w}=-\nu\left(u_{2}-u\right)$, so that (21) becomes:

$$
\Delta\left(m c_{Q}+\mu^{p}\right)=-\frac{1-\Gamma}{\Gamma}\left[\bar{\psi} u+\left(\bar{\phi}_{21}+\nu\right)\left(u_{2}-u\right)+\rho \bar{\phi}_{21} u_{2} i r+\frac{\rho^{2}}{2} \bar{\phi}_{21} u_{2} i r^{2}\right]+\alpha \Delta s_{Q}
$$

Notice that the term in $u_{2}-u$ plus the two interaction terms in $u_{2}$ and $i r$ are the new variables that our model adds to the specification proposed by BG (2007) in a similar model without immigration. The intuition behind these novel effects is as follows. First, insofar as the unemployment rate of immigrants is higher than the unemployment rate of natives, this will induce a reduction in the marginal cost both via lower wages -because immigrants have a less elastic labor supply than natives ${ }^{18}$ and through a reduction in the wage markup set by unions. Further, in our model the interaction terms give rise to the convenient property that the effects of the $u_{2}-u$ gap depend on the size of the immigration rate in the economy: the higher is the immigration rate the larger will be the reduction in inflation brought about by the unemployment rate differential. In other words, these effects on the marginal cost will be larger in economies with large immigration than in those with low immigration.

\footnotetext{
${ }^{18}$ Think of a negative labor demand shift: wages fall more the less elastic is labor supply. Here the shift is one that reduces immigrants' employment more than natives'.
} 


\subsubsection{Gross output and GDP deflators}

Before turning to the final specification of the NKPC equation, a final issue to be addressed is that, according to our interpretation of $Q$ in (1), equation (22) yields the determinants of the marginal cost of producing gross output, rather than value added (GDP). Since a time series of the gross output deflator, $p_{Q}$, is not available for Spain, we need to reinterpret (22) in terms of the GDP deflator, $p$, which is the series used in the empirical section below. The assumption of a Cobb-Douglas production function in (1) implies separability between raw materials and the labor input used to produce GDP. Hence, it follows that $\Delta\left(m c_{Q}+\mu^{p}\right)=\Delta\left(m c+\mu^{p}\right)$, where $m c$ is the real marginal cost of producing GDP. Consequently, the only variable in the right-hand-side of (22) that needs to be changed is the real price of raw materials, $s_{Q}$, which was deflated by $p_{Q}$. To replace $p_{Q}$ by $p$ in this real price, we make use of the fact the former price index is implicitly defined by $p_{Q}=(1-\chi) p+\chi p_{m}$ or $p_{Q}=p+\chi s_{m}$, where $s=p_{m}-p$ and $\chi$ is the share of imports in nominal gross output, as reported in the national accounts. Hence, the changes in $s_{Q}$ and $s$ are related by

$$
\Delta s_{Q}=\Delta s-\left(\Delta p_{Q}-\Delta p\right)=\Delta s-\chi\left(\Delta p_{m}-\Delta p\right)=(1-\chi) \Delta s
$$

Substitution of (23) into (22) yields the final specification of the real marginal cost of producing GDP

$$
\Delta\left(m c+\mu^{p}\right)=-\frac{1-\Gamma}{\Gamma}\left[\bar{\psi} u+\left(\bar{\phi}_{21}+\nu\right)\left(u_{2}-u\right)+\rho \bar{\phi}_{21} u_{2} i r+\frac{\rho^{2}}{2} \bar{\phi}_{21} u_{2} i r^{2}\right]+\alpha(1-\chi) \Delta s .
$$

Notice that there is a difference between the shares of raw materials $\alpha$ and $\chi$. As argued above, we have that $\chi=P_{m} M / P_{Q} Q$, whereas, denoting capital compensation by $r K, \alpha=P_{m} M /\left(P_{Q} Q-r K\right)$, since capital has been ignored as an input of $Q$ in (1). Therefore, $\chi<\alpha$. In any case, the coefficient on $\Delta s$ in the above equation is positive since $\alpha(1-\chi)>0$.

An important feature of (23) is that the marginal cost of producing GDP has a unit root as long as $0<\Gamma<1$, i.e. $0<\gamma<1$. As will be shown below, this implies that the NKPC has the appealing property that inflation is in the long run independent of real factors, which only influence the change in inflation. As explained in Appendix A.4, the 
insight behind this property is the presence of real rigidities, either in wages (as in the present model) or in price setting.

\subsection{Alternative specifications of the NKPC}

Once the evolution of the real marginal cost has been derived, the last step is to obtain an NKPC linking it to inflation. For that, we use the two well-known alternatives proposed by Galí and Gertler (1999): the forward-looking model (FNPC) and the hybrid (i.e., a combination of forward and backward-looking price-setters) model (HNPC). These two specifications are given (introducing time subscripts), respectively, by

$$
\begin{gathered}
\pi_{t}=\beta E_{t} \pi_{t+1}+\kappa_{f}\left(m c_{t}+\mu^{p}\right) \\
\pi_{t}=\frac{\beta \theta}{\tau} E_{t} \pi_{t+1}+\frac{\varsigma}{\tau} \pi_{t-1}+\frac{\kappa_{h}}{\tau}\left(m c_{t}+\mu^{p}\right),
\end{gathered}
$$

where $\pi_{t}\left(\equiv p_{t}-p_{t-1}\right)$ is the inflation rate in period $t, E_{t} \pi_{t+1}$ is the (rational) expectation of inflation in $t+1$ conditional on all information available up to $t, \kappa_{f}=(1-\beta \theta)(1-\theta) / \theta$, $\kappa_{h}=(1-\varsigma)(1-\beta \theta)(1-\theta)$, and $\tau=\theta+\varsigma[1-\theta(1-\beta)]$. In these expressions, $\beta$ is the discount rate, $1-\theta$ is the probability that firms are allowed to optimally reset prices in period $t$ according to Calvo's (1983) model, and $\varsigma$ is the proportion of firms which use the simple backward-looking rule of thumb proposed by Galí and Gertler (1999). ${ }^{19}$

Substituting (22) into (25) and (26) yields the two final specifications of the NKPC with immigration that we estimate below. The forward-looking $\mathrm{PC}$ with immigration (FNPCI) is

$$
\begin{aligned}
\pi_{t}= & \psi_{1}^{f} E_{t} \pi_{t+1}+\psi_{2}^{f} \pi_{t-1}-\frac{(1-\Gamma) \kappa_{f}}{(1+\beta) \Gamma}\left[\bar{\psi} u_{t}+\left(\bar{\phi}_{21}+\nu\right)\left(u_{2 t}-u_{t}\right)\right. \\
& \left.+\rho \bar{\phi}_{21} u_{2 t} i r_{t}+\frac{\rho^{2}}{2} \bar{\phi}_{21} u_{2 t} i r_{t}^{2}\right]+\frac{\alpha(1-\chi) \kappa_{f}}{1+\beta} \Delta s_{t}
\end{aligned}
$$

with $\psi_{1}^{f}=\beta /(1+\beta)$ and $\psi_{2}^{f}=1 /(1+\beta)$. Hence, everything else equal, (27) establishes a tradeoff between the change in inflation, $\Delta \pi$, and the unemployment rate, $u$. In this specification both the intercept and the slope (with respect to $u_{t}$ ) of the standard PC are shifted by the presence of immigrants. In effect, in the absence of immigration (i.e.

\footnotetext{
${ }^{19}$ As discussed in Appendix A.4 a similar NKPC can be derived using Rotemberg's (1982) quadratic adjustment cost model of changing prices.
} 
$\bar{\phi}_{21}=\nu=0$ and $\left.\bar{\lambda}=1\right)$, the slope of the $\mathrm{PC}$ in the $(\Delta \pi, u)$ plane will be $-\frac{\kappa_{f}(1-\Gamma)}{\Gamma(1+\beta)} \phi_{1}$, since $\bar{\psi}=\phi_{1}$ when $\bar{\phi}_{21}=0$, as in BG. By contrast, with immigration, for given values of $u_{2}$ and $i r$, the slope becomes $-\frac{\kappa_{f}(1-\Gamma)}{\Gamma(1+\beta)}\left(\bar{\psi}-\bar{\phi}_{21}-\nu\right)=-\frac{\kappa_{f}(1-\Gamma)}{\Gamma(1+\beta)}\left(\phi_{1}-\nu\right)$ so that the $\mathrm{PC}$ is flatter than in the previous case. Likewise, with immigration the intercept shifts downwards by $-\frac{\kappa_{f}(1-\Gamma)}{\Gamma(1+\beta)}\left[\left(\bar{\phi}_{21}-\nu\right) u_{2 t}+\rho \bar{\phi}_{21} u_{2 t} i r_{t}+\frac{\rho^{2}}{2} \bar{\phi}_{21} u_{2 t} i r_{t}^{2}\right]$. Notice that both changes are therefore in line with the evolution of the Spanish PC during the last decade or so, as shown in Figure 1.

The hybrid PC with immigration (HNPCI), in turn, becomes:

$$
\begin{aligned}
\pi_{t}= & \psi_{1}^{h} E_{t} \pi_{t+1}+\psi_{2}^{h} \pi_{t-1}+\psi_{3}^{h} \pi_{t-2}-\frac{\tau(1-\Gamma) \kappa_{h}}{(\tau+\beta \theta) \Gamma}\left[\bar{\psi} u_{t}+\left(\bar{\phi}_{21}+\nu\right)\left(u_{2 t}-u_{t}\right)\right. \\
& \left.+\rho \bar{\phi}_{21} u_{2 t} i r_{t}+\frac{\rho^{2}}{2} \bar{\phi}_{21} u_{2 t} i r_{t}^{2}\right]+\frac{\alpha \tau(1-\chi) \kappa_{h}}{\tau+\beta \theta} \Delta s_{t},
\end{aligned}
$$

with $\psi_{1}^{h}=\beta \theta /(\tau+\beta \theta), \psi_{2}^{h}=(\tau+\varsigma) /(\tau+\beta \theta)$, and $\psi_{3}^{h}=-\varsigma /(\tau+\beta \theta)$. Thus, $\psi_{1}^{h}+\psi_{2}^{h}+\psi_{3}^{h}=$ 1, so that, as before, the NKPC becomes vertical in the long run.

Inspection of (27) shows that this specification leads to the presence of forward and backward components of inflation in the NKPC without having to rely on the existence of firms which use a simple backward-looking rule of thumb to set prices. By contrast, when this type of firms is considered in (28), the backward component of inflation has two lags, the first one with a positive coefficient and the second one with a negative coefficient. These implications will be used to discriminate between these two alternative specifications of the NKPC.

Given the long-run neutrality property, we can define the concept of fundamental change of inflation, $\Delta \pi_{t}^{*}$, along the lines of Galí and Gertler (1999) and Galí et al. (2001), to then integrate this variable forward in order to compute the fundamental level of inflation, $\pi_{t}^{*}$. In what follows we illustrate this procedure with the FNPCI specification, since the approach for the HNPCI is similar but more cumbersome. First, by iterating (27) forward, we obtain

$$
\Delta \pi_{t}^{*}=(1+\beta) \sum_{j=0}^{\infty} \beta^{j} E_{t}\left\{\widehat{x}_{t+j} \mid z_{t}\right\},
$$


where in our empirical application, $z_{t}=\left[\widehat{x}_{t}, \widehat{x}_{t-1}, \widehat{x}_{t-2}, \pi_{t}, \pi_{t-1}, \pi_{t-2}\right]$ and

$$
\begin{aligned}
\widehat{x}_{t}= & -\frac{(1-\Gamma) \kappa_{f}}{(1+\beta) \Gamma}\left[\bar{\psi} u_{t}+\left(\bar{\phi}_{21}+\nu\right)\left(u_{2 t}-u_{t}\right)\right. \\
& \left.+\rho \bar{\phi}_{21} u_{2 t} i r_{t}+\frac{\rho^{2}}{2} \bar{\phi}_{21} u_{2 t} i r_{t}^{2}\right]+\frac{\alpha(1-\chi) \kappa_{f}}{1+\beta} \Delta s_{t} .
\end{aligned}
$$

Next, we construct $\widehat{x}_{t}$ using the coefficients in our estimated FNPCI and, to compute forecasts of its future values, we run a second-order vector autoregression of the bivariate system formed by $\Delta \pi_{t}$ and $\widehat{x}_{t}$. Letting $A$ denote the companion matrix of the $\operatorname{VAR}(1)$ representation of $z_{t}$, we have that $E_{t}\left\{\widehat{x}_{t+j} \mid z_{t}\right\}=e_{1}^{\prime} A^{j} z_{t}$, where $e_{1}$ is a vector with 1 in its first position and zeros elsewhere. Hence:

$$
\Delta \pi_{t}^{*}=(1+\beta) e_{1}^{\prime}(I-\beta A)^{-1} z_{t}
$$

using the standard result that $\Sigma_{j=0}^{\infty} \beta^{j} A^{j}=(I-\beta A)^{-1}$ for a matrix $A$ with eigenvalues less that unity.

\section{$5 \quad$ Empirical results}

In this section we present our estimates of the model. We estimate first the forwardlooking specification in equation (27):

$$
E_{t}\left\{\left[\pi_{t}-\alpha_{1} \pi_{t+1}-\alpha_{2} \pi_{t-1}-\alpha_{3} u_{t}-\alpha_{4}\left(u_{2 t}-u_{t}\right)-\alpha_{5} u_{2 t} i r_{t}-\alpha_{6} u_{2 t} i r_{t}^{2}-\alpha_{7} \Delta s_{t}\right] Z_{t}\right\}
$$

by the Generalized Method of Moments (GMM), using a set of instruments, $Z_{t}$, consisting of a constant and, as is standard in the literature (see e.g. Galí et al., 2003), four lags of the following variables: the inflation rate $\left(\pi_{t}\right)$, the relative unemployment rate of immigrants $\left(u_{2 t}-u_{t}\right)$, the log share of immigrants in employment $\left(i r_{t}\right)$, the inflation rate of imported inputs $\left(\Delta s_{t}\right)$-which proxies for the total intermediate input prices that appear in the model--, and the labor income share. We also include two lags of the following variables: cyclical output (with the trend estimated with the Hodrick-Prescott filter using a parameter of 1,600) and of an index of the degree of globalization of the Spanish economy. ${ }^{20}$ Detailed definitions of all variables appear in Appendix B. The data

\footnotetext{
${ }^{20}$ The higher the degree of globalization, the higher should be the immigrant flow, e.g. attracted by foreign investment.
} 
start in 1980:1 but given the lead and lags involved, our effective estimation period is 1982:1-2006:3. There is no data on the split of the labor force between natives and immigrants before 1987:2, which forces us to assume that they had the same unemployment rate through that date. However, this is not an important limitation since during that period immigration only represented $0.3 \%$ of the labor force on average.

Column (1) in Table 1 presents the estimated coefficients in the unrestricted specification of equation (27). All coefficients are statistically significant and have the expected signs. In particular, the relative immigrant unemployment rate and the interactions of the immigrants' unemployment rate with their (logged) share in employment and its square all have negative effects on inflation, as predicted by the model. In other words, the negative signs on these estimated coefficients indicate that our claim that immigrants have a lower labor supply elastiticy than natives $\left(\bar{\phi}_{21}>0\right)$ is strongly supported by the data. The unrestricted value of the discount rate $\beta$ implied by the coefficient on lagged inflation is 0.972 , which is higher and more realistic than those found in the literature. For instance, Galí et al. (2003) find values between 0.84 and 0.92 for the Euro area and Galí and López-Salido (2001) between 0.75 and 0.85 for Spain over 1990-1998. To check whether this model is appropriate, we perform several tests of our proposed specification in (27) against the most relevant modelling alternatives discussed before, namely: (i) constant vs. decreasing returns to scale in (1) (see footnote 11), (ii) a linear vs. a concave shape of immigrant workers' labor supply (see footnote 12), and (iii) the unemployment rate gap against the labor force differential as the determinant of the wage markup (see Appendix A.3). As regards (i), following BG (Appendix 3), we included the first differences of $u_{t}$ and $u_{2 t}-u_{t}$ as additional regressors in (27) and tested for the joint significance of their coefficients; this yielded a $p$-value of 0.132 in the corresponding $\chi^{2}(2)$ test, so that we are not able to reject the null of constant returns to scale. With regard to (ii), a quadratic term in $u_{2 t}-u_{t}$ was added; again its estimated coefficient was not statistically significant $(t$-ratio $=1.35) .{ }^{21}$ Finally, regarding (iii), we added the rela-

\footnotetext{
${ }^{21}$ As pointed out earlier, immigrant workers in Spain tend to achieve similar unemployment rates as natives five years after arrival. Thus, lack of concavity in relative unemployment may mean higher inflation pressure in the future. However, as also mentioned, even after their assimilation period, immigrants are over-represented in temporary and low-skilled jobs, for which they are overqualified.
} 
tive labor force, $\ell_{2 t}-\ell_{t}$, to the list of regressors, obtaining once more a non-significant effect $(t$-ratio $=1.13)$. In view of these results, we keep $(27)$ as our preferred unrestricted model, which we use for testing the remaining restrictions implied by the underlying structural parameters.

In Column (1), the sum of the coefficients on future and lagged inflation is very close to unity, as implied by the model. A Wald test of this null hypothesis yields a $p$-value of 0.22 . Thus we impose this restriction to gain efficiency, with a value for the coefficient on lagged inflation of 0.490 , implying a value for $\beta$ of 0.961 . Column (2) shows the restricted estimates, which are very similar to those in Column (1). This set of results allows us to account for the flattening of the standard PC (i.e. the slope of inflation vis-à-vis unemployment) by the presence of the new term in the relative unemployment rate of immigrants. The slope falls from -0.112 to -0.032 , so that the PC becomes significantly flatter. We also saw in Figure 1 that there were shifts in the intercept of the PC. If we take the stable PC traced for the period before the rise in immigration that is apparent in the graph, i.e. from 1990:1 to 1994:1, and compare its intercept to that of the subsequent stable locus, from say 1998:4 to 2006:4, we find that it shifts downwards by 0.44 percentage points per year, due to the introduction of the three immigration-related variables. ${ }^{22}$ Alternatively, since average inflation during 19992006 was $3.8 \%$, this implies that, in the absence of immigration, inflation on average would have been $4.24 \%$ exclusively due to this effect. Although this represents about a $12 \%$ decrease in annual inflation, it is admittedly not a very large reduction if we look again at Figure 1. Thus, we can conclude that our estimation results attribute most of the displacement of the $\mathrm{PC}$ due to immigration to the reduction in its slope rather than to the drop in the intercept.

\section{TABLE 1 ABOUT HERE}

\footnotetext{
This may reduce inflationary pressure since the real unit labor costs associated to these jobs are lower.

${ }^{22}$ Computed as the difference across averages over those two periods of the expression: $\widehat{\alpha}_{4} u_{2 t}+$ $\widehat{\alpha}_{5} u_{2 t} i r_{t}+\widehat{\alpha}_{6} u_{2 t} i r_{t}^{2}$.
} 


\subsection{Structural parameters and fundamental inflation}

The estimation of equation (31) yields six estimated coefficients (imposing $\alpha_{1}+\alpha_{2}=1$ ), while from (27) we have the following ten free parameters: $\beta, \gamma, \alpha, \chi, \theta, \bar{\lambda}, \phi_{2}, \phi_{1}, \rho$, and $\nu$. To check how sensible our estimation is, we calibrate $\alpha, \chi$, and $\bar{\lambda}$ to their average values in the Spanish economy, plus a range of plausible values of the (inverse) Frisch labor supply elasticities of immigrants and native workers, $\phi_{2}$ and $\phi_{1}$. In this way, we are able to identify some of the underlying structural parameters: $\beta, \theta, \rho$, and $\nu$ (see Appendix A.4 for details). ${ }^{23}$ We obtain a value for $\theta$, the fraction of firms that keep their prices unchanged per quarter, of 0.810, which is in line with the estimates of Galí et al. (2003) for the Euro area (from 0.78 to 0.87) and of Galí and López-Salido (2001) for Spain (from 0.84 to 0.91 ). Our quarterly estimate of $\theta$ implies that the average time over which a price is fixed, given by $1 /(1-\theta)$, is 1.3 years. This is close to the survey evidence about the price-setting behavior of Spanish firms at the end of our sample period (2003-2004) reported in Fabiani et al. (2006), according to which the average duration of unchanged prices in Spain is one year.

As for the remaining parameters, we obtain an elasticity of substitution between native and immigrant workers of $\sigma=1.277(\rho=0.217)$, which implies that they are gross substitutes but not too far from the Cobb-Douglas case $(\sigma=1)$. Under the plausible assumption that $\phi_{1}$ is unity, the implied estimate of the effect of immigration on the wage markup is $\nu \simeq 0.7$, being rather robust to a wide range of larger values of $\phi_{2}$, so that for each percentage point increase in immigration the wage markup decreases by about 0.7 percentage points. We do not have any other empirical evidence in the literature to check how sensible this finding is, though it agrees with the fact that the growth of real wages has been negative since the mid-1990s, when the Spanish economy entered a long expansion.

In order to check how the model explains the evolution of inflation, we estimate the

\footnotetext{
${ }^{23}$ Notice that an estimate of the real wage sluggishness, $\gamma$, cannot be directly identified from (27). However, an indirect estimate can be recovered from the coefficient of the lagged dependent variable, $\omega_{t-1}$, when estimating by GMM the partial adjustment model for the real wage in (12), with four lags of the regressors as instruments. This yields $\widehat{\Gamma}=0.713(t$-ratio $=12.56)$. Hence, using $\Gamma=\frac{\gamma}{1-\alpha+\gamma \alpha}$ with the calibrated value for $\alpha=0.536$ (see Appendix A.4), we get $\widehat{\gamma}=0.535(t$-ratio $=7.43)$.
} 
fundamental inflation rate as described in Section 4. To compute forecasts of a single right-hand side variable determining inflation we use the coefficients presented in column (2) of Table 1. We then run a second-order vector autoregression of inflation changes and the deviations of $x_{t}$ from its sample mean, and then apply equation (30), which is integrated forward. As can be observed, the resulting fundamental inflation, shown in Figure 6, tracks observed inflation well.

\section{FIGURE 6 ABOUT HERE}

We now focus on the eight-year period since the beginning of 1999, when Spain joined the Euro alongside ten other countries. Over this period inflation increased from $2.4 \%$ in 1998:4 to $4.5 \%$ in $2001: 1$ and then steadily fell to $3.5 \%$ in $2006: 4$, while the unemployment rate fell by 7 percentage points (p.p.), which represents a very favorable tradeoff for the Spanish economy by historical standards. Over the same period, the relative unemployment rate of immigrants rose by 3 p.p., the immigrant share in employment increased by a massive 12 p.p., and the price of imported inputs rose by 0.4 p.p. in net, with sharp variations up and down.

Over this period fundamental inflation overpredicts actual inflation by 0.4 p.p. annually. Thus, there is still some extra reason for the moderate behavior of inflation that our model cannot account for. A natural candidate is the anchoring of inflation expectations due to the operation of the single monetary policy in the Euro area. ${ }^{24}$

To compute their contribution to fundamental inflation, we shut out in turn the unemployment rate, the three terms in the immigrant's unemployment rate, and the imported input inflation rate in the equation determining the fundamental inflation rate. The results from this exercise are quite revealing. Rescaling by the average observed inflation rate of $3.8 \%$ per year, we find that without the contribution of the falling unemployment rate, inflation would have been 2.5 p.p. lower annually whereas, without the composite contribution of the immigrant unemployment terms, inflation would have

\footnotetext{
${ }^{24}$ Indeed, recursive estimation of (27) indicates that from 2002 onwards the coefficient on future inflation has been smoothly rising whereas the coefficient on lagged inflation has gone down, without violating the long-run neutrality restriction. However, we have not been able to identify any variable which helps to pin down these effects.
} 
been 2.2 p.p. higher on average every year, out of which about $20 \%$ (0.44 p.p.) is due to the drop in the intercept of the PC and the remaining $80 \%$ to the chages in its slope. Thus, over this particular period, about $85 \%$ of the increase in inflation derived from the reduction in the overall unemployment rate was compensated by the effects of the increase of the unemployment rate of immigrants and their share in employment. Lastly, the contribution of imported input prices to inflation has been marginal relative to the effect of immigration, since up the 2006 there have not been major inflationary pressures from imported raw materials, as has been the case later on.

\subsection{Robustness checks}

As a robustness check, to account for variability of the price markup (so far assumed constant) we also introduced cyclical output as an additional regressor in (27), but its coefficient was not significant (with a $t$-ratio of 1.20). We also estimate the hybrid NKPC in equation (28). The results are shown in Column (3) of Table 1. While the coefficients on the lead and lags of inflation are very close to adding up to 1, it turns out that the coefficient on $\pi_{t-2}$ is positive. This coefficient corresponds to $-\varsigma /(\tau+\beta \theta)$ in the model, thereby implying that the fraction of firms following a rule of thumb, $\varsigma$, is negative and therefore meaningless. Imposing the restriction on the sum of coefficients does not solve this problem either. Thus, we discard the HNPCI specification in favour of the FNPCI specification.

Lastly, it is worth comparing the performance of our proposed equation with the open-economy versions of the standard models of the NKPC popularized by Gali and Gertler (1999). As mentioned above, these are the forward-looking (FNPC) and the hybrid (HNPC) equations in (25) and (26), where the real marginal cost is captured by the (logged) aggregate labor income share, $s_{L}$, and the relative price of imported materials and labor, that is: $m c=s_{L}+\xi\left(p_{m}-w\right)$. As discussed in Rotemberg and Woodford (1999), the parameter $\xi$ is zero when the production function is Cobb-Douglas whereas, using instead a CES specification, it is positive when the elasticity of substitution between labor and intermediate goods is above unity, as is often found in the literature. These equations were applied by Galí and López-Salido (2001) to estimate the NKPC 
for Spain over 1980-1998, yielding a good fit and sensible estimates of the underlying structural parameters that we also found with our dataset. Since their estimation period ends before immigration surged, it is interesting to check how these models perform up to the end of our sample period, 2006:3. Estimating by GMM with their instrument set yields, for the FNPC: ${ }^{25}$

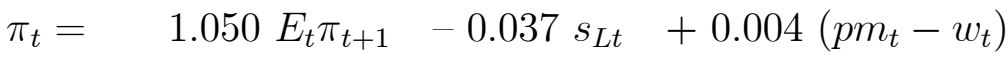

$$
\begin{aligned}
& \text { (31.10) (3.31) (1.65) }
\end{aligned}
$$

and for the HNPC:

$$
\pi_{t}=0.410 E_{t} \pi_{t+1}+0.629 \pi_{t-1}+0.010 s_{L t}-0.004\left(p m_{t}-w_{t}\right)
$$

where $t$-ratios are reported in parentheses. In both regressions, the implied value of $\beta$ is above unity, violating the restriction that both the coefficient on $E_{t} \pi_{t+1}$ (i.e., $\beta$ ) in (25) and the sum of the coefficients on $E_{t} \pi_{t+1}$ and $\pi_{t-1}$ (i.e., $\left.(\beta \theta+\zeta) / \tau\right)$ in $(26)$ should be smaller than 1. Moreover, the estimated coefficient on $s_{L t}$ is negative and significant in (32) and positive but non-significant in (33), while the coefficient on the relative price changes sign across the two specifications. These results turn out to be robust to imposing a value of $\beta$ in a plausible range between, say, 0.90 and 1. For example, for $\beta=0.99$, we get, for the FNPC:

$$
\pi_{t}=\begin{array}{ccc}
0.99 E_{t} \pi_{t+1} & -0.029 s_{L t} & +0.007 \\
(-) & (2.92) & (5.88)
\end{array}\left(p m_{t}-w_{t}\right)
$$

and for the HNPC:

$$
\begin{aligned}
& \pi_{t}=0.358 E_{t} \pi_{t+1}+0.639 \pi_{t-1}+0.004 s_{L t}-0.002\left(p m_{t}-w_{t}\right) \\
& \text { (9.98) (9.98) (0.76) (2.40) }
\end{aligned}
$$

Therefore, applying the standard models of the NKPC -which ignore differences between immigrant and native workers- does not work once the sample is extended to include the immigration boom in the Spanish labor market, which provides some further support to our approach.

\footnotetext{
${ }^{25}$ The instruments set includes a constant plus four lags of price and wage inflation, relative prices, detrended output, and the labor share.
} 


\section{Industry-specific NKPCs}

Since the previous results for the aggregate economy seem to confirm the moderating effect of immigration on inflation, our reasoning would be reinforced if, when estimating NKPCs at the industry level, this effect was larger for those industries with higher intensity of immigrant labor. Using information from the Spanish Labor Force Survey (EPA), we are able to obtain a breakdown of employment by nationality for three large industries: manufacturing, construction, and services. ${ }^{26}$ This, together with the information on industry GDP and price deflators from the Spanish National Accounts, allows us to compute industry inflation measures, plus industry labor shares and cyclical output, to be used as instrumental variables. Since industry unemployment is not a well-defined concept, we use aggregate measures of $u_{t}$ and $u_{2 t}-u_{t}$ in the industry specification of equation (27). Nevertheless, to the extent that there is labor mobility across industries, these aggregate measures of unemployment are bound to capture some of their traditional disciplinary effects on inflation. Furthermore, $u_{2 t}$ is interacted with the immigration rate, $i r_{t}$, measured for each of the industries.

Table 2 reports the estimation results for the (restricted) FNPCI in these three industries, where we have imposed the value of the discount factor estimated before, i.e. $\beta=0.961$, which is not statistically rejected in the unrestricted estimation. Interestingly, the effect of the relative unemployment rate and the interaction terms is much larger and significant in the services industry, where $62 \%$ of the migrants work (specially in home services, and hotels and catering), than in construction and manufacturing, where $19 \%$ and $12 \%$ of immigrants work, respectively (over 2000-2006, where the immigrant stock starts to be significant). Therefore, this fragmentary evidence seems to go in the same direction as our previous results.

\section{TABLE 2 ABOUT HERE}

\footnotetext{
${ }^{26}$ We exclude agriculture because price-setting in this sector is highly affected by subsidies and supply shocks, and so our model does not describe it well.
} 


\section{Conclusions}

This paper examines the evolution of the Phillips curve for the Spanish economy since the early 1980s. In particular, we focus on what has happened since the late 1990s. Starting from 1999 the unemployment rate fell by almost 7 percentage points, while inflation remained relatively subdued around a plateau of $2 \%-4 \%$. Thus, the slope of the PC has become much flatter. We argue that this favorable evolution is largely due to the impact on the labor market of the huge rise in the immigration rate, from $1 \%$ of the population in 1995 to $9.3 \%$ in 2006. We derive a New Keynesian Phillips curve accounting for the effects of immigration, a variable which is found to shift the curve if preferences towards labor supply or the bargaining power of immigrants and natives differ. In particular, we find that the relative unemployment rate of immigrants with respect to the national unemployment rate and the interaction of the immigrant unemployment rate with their share in employment, in levels and squared, enters the PC, so that both its intercept and slope is shifted by the presence of immigration.

By estimating our NKPC model with quarterly data for Spain over the period 19822006, we are able to confirm that the variables in which the immigrant unemployment rate enters are significant determinants of the $\mathrm{PC}$ and that conventional models of the NKPC which treat labor as an homogeneous input do not fit the data well. Our estimation results attribute most of the displacement of the $\mathrm{PC}$ to the reduction in its slope, which according to our model is due to the reduction in the bargaining power of workers induced by immigration, rather than to the drop in the intercept, which comprises the other channels considered in the model. We also find that while the fall in the average unemployment rate over the last 8 years caused the inflation rate to increase by 2.5 percentage points per year, the surge in immigration accounts for an offsetting 2.2 percentage-point drop in the inflation rate per year. Lastly, we also estimate industryspecific PCs, finding that the impact of the relative immigrant unemployment rate is larger for industries with a higher share of immigrant employment. These effects may decay over time, as immigrants integrate and their labor supply behavior becomes closer to that of natives, but it is too soon to detect such evolution in the case of Spain. 
In this respect, the effect of immigration on inflation is good news for central banks. Yet, as Bean (2006) argues, the flattening of the PC is rather more of a mixed blessing since, on the one hand, it implies that demand shocks and policy mistakes will not show up in large movements of inflation but, on the other, if inflation remains above target, like is the case nowadays (after this paper was written) a deeper slowdown and/or, as our results point out, increasing immigration flows -to lower wage inflation pressurewill be required to bring it down. 


\section{A Appendix. Some derivations}

\section{A.1 Derivation of $\bar{\lambda}$}

Consider the following approximation of the (log) deviation of a variable $X$ from its steady state value, $\bar{X}$, where we omit time subscripts for notational simplicity: $\widehat{x}=$ $\ln (X / \bar{X}) \simeq(X-\bar{X}) / \bar{X}$, so that $X=\bar{X} \exp (\widehat{x}) \simeq \bar{X}(1+\widehat{x})$, and for any power $a$ of $X$, $X^{a}=\bar{X}^{a} \exp (\widehat{x}) \simeq \bar{X}(1+a \widehat{x})$. Then, since aggregate employment is given by (2), use of the previous approximation yields

$$
\bar{N}^{\rho}(1+\rho \widehat{n})=\delta_{1}{\overline{N_{1}}}^{\rho}\left(1+\rho \widehat{n}_{1}\right)+\delta_{2}{\overline{N_{2}}}^{\rho}\left(1+\rho \widehat{n}_{2}\right) .
$$

Since, in steady state, $\bar{N}^{\rho}=\delta_{1}{\overline{N_{1}}}^{\rho}+\delta_{2}{\overline{N_{2}}}^{\rho}$ and $\delta_{1}+\delta_{2}=1$, it is straightforward to show that

$$
\widehat{n}-\widehat{n}_{2}=\bar{\lambda}_{n}\left(\widehat{n}_{1}-\widehat{n}_{2}\right)
$$

where $\bar{\lambda}_{n}=\delta_{1}\left(\bar{N}_{1} / \bar{N}\right)^{\rho}$.

Next, given (2), the corresponding aggregate wage index, $W$, satisfies

$$
W^{-\frac{\rho}{1-\rho}}=\delta_{1}^{\frac{1}{1-\rho}} W_{1}^{-\frac{\rho}{1-\rho}}+\delta_{2}^{\frac{1}{1-\rho}} W_{2}^{-\frac{\rho}{1-\rho}} .
$$

Using the same steps as before, we obtain the following expression for the (log) deviations of real wages from steady state,

$$
\widehat{\omega}-\widehat{\omega}_{2}=\bar{\lambda}_{\omega}\left(\widehat{\omega}_{1}-\widehat{\omega}_{2}\right),
$$

where $\bar{\lambda}_{\omega}=\delta_{1}^{\frac{1}{1-\rho}}\left(\widehat{W}_{1} / \bar{W}\right)^{-\frac{\rho}{1-\rho}}$.

Finally, computing the marginal products in the production function in (1) with respect to $N$ and $N_{1}$ in steady state and equating them to $\bar{W}$ and $\bar{W}_{1}$, implies that

$$
\delta_{1}\left(\frac{\bar{N}_{1}}{\bar{N}}\right)^{-(1-\rho)}=\frac{\bar{W}_{1}}{\bar{W}}
$$

whereby

$$
\delta_{1}\left(\frac{\bar{N}_{1}}{\bar{N}}\right)^{\rho}=\delta_{1}^{\frac{1}{1-\rho}}\left(\frac{\widehat{W}_{1}}{\bar{W}}\right)^{-\frac{\rho}{1-\rho}} .
$$

Hence, $\bar{\lambda}_{n}=\bar{\lambda}_{\omega} \equiv \bar{\lambda}=\delta_{1}\left(\bar{N}_{1} / \bar{N}\right)^{\rho}=1-\delta_{2}\left(\bar{N}_{2} / \bar{N}\right)^{\rho}=1-\delta_{2}(\overline{I R})^{\rho}$, where $\overline{I R}=\bar{N}_{2} / \bar{N}$.

\section{A.2 Second-order approximation to $\lambda(I R)$}

Let us now reinterpret the functional form of $\lambda(\overline{I R})$ derived above as the log-linearized approximation of the CES aggregator in (2) around any given value of $I R$, not necessarily its steady-state value. This yields

$$
\lambda(I R)=1-\delta_{2}(I R)^{\rho}
$$


where $I R=N_{2} / N$. Using a second-order Taylor expansion of $(I R)^{\rho}$ around $\rho=0$, i.e., the Cobb-Douglas case, we get

$$
(I R)^{\rho} \simeq 1+\rho i r+\frac{\rho^{2}}{2} i r^{2}=1+q(i r)
$$

where $i r=n_{2}-n=\ln \left(N_{2} / N\right)$ and function $q(i r)=\rho i r+\frac{\rho^{2}}{2} i r^{2}$. Notice that, around $\rho=0$, we can interpret the distributional parameters $\delta_{1}$ and $\delta_{2}$ in (2) as the weighting factors $\bar{\lambda}$ and $(1-\bar{\lambda})$ in $(5)$, since taking logs of the Cobb-Douglas aggregator $N=N_{1}^{\bar{\lambda}} N_{2}^{1-\bar{\lambda}}$ would yield the aggregation rules in (5) in exact terms. Hence, replacing the approximation into the function $\lambda(I R)$, implies that

$$
\lambda(I R) \simeq \lambda=1-(1-\bar{\lambda})[1+q(i r)]=\bar{\lambda}-(1-\bar{\lambda}) q(i r),
$$

so that $1-\lambda$ becomes

$$
1-\lambda=(1-\bar{\lambda})[1+q(i r)]
$$

Let us now examine the two terms in (19) where $1-\lambda$ appears:

(i) $\phi_{21}\left(u_{2}-u\right)$ :

$$
\begin{aligned}
\phi_{21}\left(u_{2}-u\right) & =(1-\lambda)\left(\phi_{2}-\phi_{1}\right)\left(u_{2}-u\right)=(1-\bar{\lambda})[1+q(i r)]\left(\phi_{2}-\phi_{1}\right)\left(u_{2}-u\right)= \\
& =\bar{\phi}_{21}\left(u_{2}-u\right)+\bar{\phi}_{21}\left(u_{2}-u\right) q(i r),
\end{aligned}
$$

where $\bar{\phi}_{21}=(1-\bar{\lambda})\left(\phi_{2}-\phi_{1}\right)>0$.

(ii) $\psi u$ :

$$
\begin{aligned}
\psi u & =\left[\lambda \phi_{1}+(1-\lambda) \phi_{2}\right] u=\phi_{1} u+(1-\lambda)\left(\phi_{2}-\phi_{1}\right) u= \\
& =\phi_{1} u+(1-\bar{\lambda})[1+q(i r)]\left(\phi_{2}-\phi_{1}\right) u=\left(\phi_{1}+\bar{\phi}_{21}\right) u+\bar{\phi}_{21} u q(i r) .
\end{aligned}
$$

Finally, the sum of both terms yields:

$$
\phi_{21}\left(u_{2}-u\right)+\psi u=\bar{\phi}_{21}\left(u_{2}-u\right)+\left(\phi_{1}+\bar{\phi}_{21}\right) u+\bar{\phi}_{21} u_{2} q(i r) .
$$

Thus, the above combination in terms of time-varying parameters, can be written in terms of constant parameters as long as two interaction terms, involving $u_{2} i r$ and $u_{2} i r^{2}$, are added to equation (19).

\section{A.3 Determinants of the wage markup}

To interpret the influence of migration on the (deviations of the) wage markup, $\widetilde{\mu}^{w}$, it is useful to consider the right-to-manage of wage setting model, where unions and firms bargain over the wage rate but the firm is free to choose the level of employment unilaterally (Nickell and Andrews, 1983). As is standard in this model, unions maximize the following objective function

$$
\max _{\omega} \Omega=\omega N(\omega)+\varsigma[U M-N(w)] \omega^{a},
$$


where $N(\omega)$ denotes labor demand (with $N^{\prime}(\omega)<0$ ), $U M$ the number of union members, and $\omega^{a}$ the alternative wage, such that the relative influence of non-employed union members is $\varsigma<1$. The maximization problem results in the following first-order condition:

$$
N^{\prime}(\omega)\left(\omega-\varsigma \omega^{a}\right)+N=0,
$$

which is the wage-setting curve. Exogenous shifts in labor supply $(L)$ influence the position of this curve through their effect on the alternative wage, defined as:

$$
\omega^{a}=\frac{N}{L} \omega+\left(1-\frac{N}{L}\right) b \omega
$$

That is, a non-employed worker has a chance to find a job and earn $\omega$ or to remain nonemployed and get an unemployment benefit which is a fraction $b$ of the wage. Replacing this expression into the wage-setting curve gives

$$
N^{\prime}(\omega) \omega\left[1-b \varsigma-\varsigma(1-b) \frac{N}{L}\right]+N=0
$$

which is upward sloping in the $\omega-L$ space if $N^{\prime \prime}(\omega) \omega+N^{\prime}(\omega)<0$, a condition that is satisfied by linear and concave labor demand functions. The equilibrium values of $\omega$ and $N\left(\omega^{*}\right.$ and $\left.N^{*}\right)$ are determined by equating the above upward-sloping wage-setting curve and the downward-sloping labor demand function $N^{\prime}(\omega)$, where unemployment is given by $L-N^{*}\left(\omega^{*}\right)$. An increase in labor supply gives rise to rightward shifts of both the wage-setting curve and the labor supply curve, inducing an unambiguous fall in wages and an ambiguous effect on unemployment. To the extent that wages are determined in a non-competitive way in this model, we loosely interpret this reduction in wages as a fall in the wage markup.

We assume that the labor supply shift is either captured by the differential in the (logged) labor forces, $\ell_{2}-\ell$, or by the gap in the unemployment rates, $u_{2}-u$, since migrants often enter unemployment when they arrive. Since $\ell_{2}-\ell$ had a positive and non-significant estimated coefficient when introduced in the NKPC, we allow $u_{2}-u$ to have an extra effect on inflation via variations in $\widehat{\mu}^{w}$, on top of its direct effect on the marginal cost.

\section{A.4 Long-run neutrality in the NKPC}

As shown by Batini et al. (2005), an isomorphic derivation of the NKPC popularized by Galí and Gertler (1999) stems from the quadratic price adjustment model proposed by Rotemberg (1982), rather than Calvo's (1983) model of constant probability of price changes. This alternative derivation has the advantage of allowing the probability of each firm resetting its prices to depend on the general level of inflation, since the costs of not doing so most certainly rise with this general level (see Ball et al., 1988). 
Let us consider the firm's problem as choosing a price path that solves

$$
\min _{p_{t+s}} \sum_{s=0}^{\infty} \beta^{s} E_{t}\left\{\frac{1}{2}\left(p_{t+s}-p_{t+s}^{*}\right)^{2}-\frac{b}{2}\left(p_{t+s}-p_{t+s-1}-c \pi_{t+s-1}^{a}\right)^{2}\right\},
$$

where the optimal price is $p_{t+s}^{*}=\mu^{p}+m c_{t+s}^{n}$, with $m c^{n}$ being the nominal marginal cost, $\pi^{a}$ denotes the general level of inflation (taken as given by the firm), and $b>0$ and $0 \leq c \leq 1$ are parameters in the loss function. When $c=1$, price adjustment costs fully depend on the deviations from the general level of inflation. Notice that the quadratic adjustment cost term in price changes implies that the higher is $\pi_{t+s-1}^{a}$ the more beneficial it is for firms to reset prices more frequently. The Euler equation (in period $t$ ) of the above minimization yields

$$
\beta b E_{t} p_{t+1}-[1-b(1+\beta)] p_{t}+b p_{t-1}=-\widehat{p}_{t},
$$

where

$$
\widehat{p}_{t}=p_{t}^{*}+c b \pi_{t-1}^{a}-\beta c b \pi_{t}^{a} .
$$

The standard solution to this Euler equation is

$$
p_{t}=\mu_{1} p_{t-1}+\left(1-\mu_{1}\right)\left(1-\beta \mu_{1}\right) \frac{\widehat{p}_{t}}{1-\beta \mu_{1} L^{-1}},
$$

where $L^{-1}$ is the forward expectations operator (e.g. $L^{-s} x_{t}=E_{t} x_{t+s}$ ) and $\mu_{1}$ is the unique stable root of $\beta b \mu^{2}-[1-b(1+\beta)] \mu+b=0$. If we now subtract from the previous solution the following identity

$$
p_{t-1} \equiv \mu_{1} p_{t-1}+\left(1-\mu_{1}\right)\left(1-\beta \mu_{1}\right) \frac{p_{t-1}}{1-\beta \mu_{1}},
$$

we obtain a new solution in terms of firm's price inflation, $\pi_{t}\left(=p_{t}-p_{t-1}\right)$ :

$$
\pi_{t}=\left(1-\mu_{1}\right)\left(1-\beta \mu_{1}\right) \frac{m c+p_{t}+c b \pi_{t-1}^{a}-\beta c b \pi_{t}^{a}}{1-\beta \mu_{1} L^{-1}}-\frac{p_{t-1}}{1-\beta \mu_{1}},
$$

where use has been made of $m c_{t}^{n}=m c_{t}+p_{t}$. Then, since in equilibrium all firms are identical (so that $\pi=\pi^{a}$ ), straightforward algebra leads to the following NKPC:

$$
\pi_{t}=\frac{\beta}{1+\beta c} E_{t} \pi_{t+1}+\frac{c}{1+\beta c} \pi_{t-1}+\frac{\left(1-\mu_{1}\right)\left(1-\beta \mu_{1}\right)}{\mu_{1}(1+\beta c)} m c_{t} .
$$

If $0<c<1$, this NKPC corresponds to the hybrid case of Galí and Gertler (1999), where we find that in the long-run steady state, $\pi_{t}=E_{t} \pi_{t+1}=\pi_{t-1}$, there is a non-zero relationship between inflation and the real marginal cost, i.e., $\pi=\frac{\left(1-\mu_{1}\right)\left(1-\beta \mu_{1}\right)}{\mu_{1}(1-\beta)(1-c)} m c$.

If $c=0$, the NKPC is equivalent to the forward-looking case of Galí and Gertler (1999), such that

$$
\pi_{t}=\beta E_{t} \pi_{t+1}+\frac{\left(1-\mu_{1}\right)\left(1-\beta \mu_{1}\right)}{\mu_{1}} m c_{t}
$$


where again, there is a long-run tradeoff given by $\pi=\frac{\left(1-\mu_{1}\right)\left(1-\beta \mu_{1}\right)}{\mu_{1}(1-\beta)} m c$.

Finally, if $c=1$, the NKPC becomes

$$
\pi_{t}=\frac{\beta}{1+\beta} E_{t} \pi_{t+1}+\frac{1}{1+\beta} \pi_{t-1}+\frac{\left(1-\mu_{1}\right)\left(1-\beta \mu_{1}\right)}{\mu_{1}(1+\beta)} m c_{t},
$$

so that inflation is independent of the real marginal cost in the long run, although it influences the change in inflation, i.e., $\Delta \pi=\frac{\left(1-\mu_{1}\right)\left(1-\beta \mu_{1}\right)}{\mu_{1}(1-\beta)} m c$.

As discussed in Section 4.5, an alternative way of obtaining long-run neutrality in the NKPC is to assume real wage sluggishness.

\section{A.5 Calibration of the parameters}

As mentioned in the main text, the estimation of equation (31) yields 6 estimated coefficients (imposing that $\alpha_{1}+\alpha_{2}=1$ ), while from (27) we have the following 10 free parameters: $\beta, \gamma, \alpha, \chi, \theta, \bar{\lambda}, \phi_{2}, \phi_{1}, \nu$, and $\rho$. Thus, we can only attempt to identify a subset of the structural parameters. As shown below, through calibration of $\alpha, \chi, \bar{\lambda}$, and the (average) labor supply elasticity of natives, $\phi_{1}$, we are able to identify $\beta, \theta, \rho$, and $\nu$. The identification procedure for each of these structural parameters involves the values of the restricted coefficients reported in Table 1 (Column 2) and, in each case, it can be summarized as follows:

( $i) \beta$, from the estimated coefficient on $E_{t} \pi_{+1}, \widehat{\psi}_{1}^{f}$, which is equal to $0.490(t$ ratio $=11.34)$. Hence, since $\psi_{1}^{f}=\frac{\beta}{1+\beta}$, the delta method yields $\widehat{\beta}=0.961$ ( $t$-ratio $=$ 11.42).

(ii) $\theta$, from the estimated coefficient of $\Delta s_{t}$ which is $\frac{\alpha(1-\chi) \kappa_{f}}{(1+\beta)}=0.005(t$-ratio $=2.77)$, with $\kappa_{f}=\frac{(1-\beta \theta)(1-\theta)}{\theta}$, using calibrated values for $\alpha$ and $\chi$, and the estimated value of $\beta$ obtained in $(i)$. It is easy to check that this yields a quadratic function in $\theta$. If we take $\alpha=0.536$ and $\chi=0.646$-computed as the average shares of imported intermediate inputs in gross output $(\alpha)$ and in gross output net of capital compensation $(\chi)$ in the Spanish economy over the period 1980-2003 according to the EU KLEMS database (www.euklems.net)- plus $\widehat{\beta}=0.961$, this yields $\widehat{\theta}=0.810(t$-ratio $=15.76)$, whereas the other root in the quadratic function is larger than unity. For this value of $\theta$, we also get $\widehat{\kappa}_{f}=0.0517(t$-ratio $=4.07)$.

(iii) $\rho$, from the ratio between the estimated coefficients on the interaction terms $u_{2} i r^{2}$ and $u_{2} i r$. From (27), this ratio yields $\widehat{\rho}=2 \frac{0.0033}{0.0307}=0.217(t$-ratio $=7.62)$. Hence, the estimated elasticity of substitution in $(2)$ is given by $\widehat{\sigma}=\frac{1}{1-0.217}=1.277(t$-ratio $=35.47)$.

(iv) $\nu$, from the ratio of the estimated coefficients on $u$ and $u_{2}-u$. This ratio yields $\frac{\bar{\psi}}{\bar{\phi}_{21}+\nu}=\frac{\phi_{1}+(1-\bar{\lambda})\left(\phi_{2}-\phi_{1}\right)}{(1-\bar{\lambda})\left(\phi_{2}-\phi_{1}\right)+\nu}=1.4$. From equations (1) and (2), with $\delta_{1}+\delta_{2}=1$, we have that $\frac{d Q}{d N_{1}}=\frac{d Q}{d N} \frac{d N}{d N^{\rho}} \delta_{1} \rho N_{1}^{\rho-1}=\frac{W_{1}}{P_{Q}}$ and $\frac{d Q}{d N_{2}}=\frac{d Q}{d N} \frac{d N}{d N^{\rho}}\left(1-\delta_{1}\right) \rho N_{2}^{\rho-1}=\frac{W_{2}}{P_{Q}}$, so that $\left(\frac{N_{1}}{N_{2}}\right)^{\rho-1}=\frac{W_{1}}{W_{2}}$, where respective markup terms would multiply the wage terms under imperfect competition. If we assume that in steady state $\frac{N_{1}}{N_{2}}=\frac{N_{1} / N}{N_{2} / N}=\frac{0.97}{0.03}=32.33$, 
taking $\rho=0.217$, we would have that $\frac{\delta_{1}}{1-\delta_{1}} 0.06576=\frac{W_{1}}{W_{2}}$. Now, to obtain a value for $\delta_{1}$ we need to assume some value for the relative wage (or relative wage plus markup). Let us take three alternatives: (a) $W_{1} / W_{2}=1 \Rightarrow \delta_{1}=0.938$, (b) $W_{1} / W_{2}=1.3 \Rightarrow \delta_{1}=0.952$, and (c) $W_{1} / W_{2}=1.5 \Rightarrow \delta_{1}=0.958$. Thus, since $\bar{\lambda}=\delta_{1}\left(\frac{N_{1}}{N}\right)^{\rho}=\delta_{1}(0.97)^{0.217}$, we have: (a) $\bar{\lambda}=0.932$, (b) $\bar{\lambda}=0.946$, and (c) $\bar{\lambda}=0.952$.

We also need to make some assumption regarding the (inverse) Frisch labor supply elasticities. If we take a value of 1 for native workers, so that $\phi_{1}=1$, as is assumed in most of the literature on NKPCs (see Galí et al., 2001, and BG), and a value of $\phi_{2}$ $=2$, from the above ratio, $\frac{\bar{\psi}}{\bar{\phi}_{21}+\nu}=1.4$, we get: (a) $\widehat{\nu}=0.695$, (b) $\widehat{\nu}=0.698$, and (c) $\widehat{\nu}=0.701$. Alternatively, if we assume use $\phi_{2}=4$, we obtain: (a) $\widehat{\nu}=0.658$, (b) $\widehat{\nu}=0.668$, and (c) $\widehat{\nu}=0.672$. Thus the value given in the text, $\widehat{\nu} \simeq 0.7$, is quite robust. 


\section{B Appendix. Variable definitions and sources}

Nominal and Real GDP. Gross Domestic Product from Spanish National Accounts produced by Instituto Nacional de Estadística (INE, www.ine.es) Base 1995, linked forward to Base 2000 at 1995:1 using growth rates. Data are seasonally adjusted and adjusted for calendar effects by INE.

Inflation. Change in GDP deflator from Spanish National Accounts by INE. Computed as quarterly change in nominal GDP minus quarterly change in real GDP.

Employment and unemployment for immigrants and natives. From the Spanish Labor Force Survey (Encuesta de Población Activa) by INE, linking 1976, 1987, 2001, and 2005 definitions. Data correspond to full-time equivalent jobs. Seasonally adjusted by INE. Workers with double nationality are considered as immigrants throughout the sample. There is no data on immigrants before 1987:2, so we assume that they have the same unemployment rate as natives through that quarter. Seasonally adjusted using Program TRAMO (Maravall, 2005).

Imported input prices. Price index for imported intermediate inputs from Ministerio de Economía y Hacienda, SERSIE Database (www.meh.es). Seasonally adjusted using Program TRAMO.

Labor share. Remuneration of employees multiplied by the ratio of employment to employees and divided by nominal GDP. This entails assuming that the self-employed earn the same labor income as employees.

Nominal wage. Remuneration of employees divided by the number of employees. The latter is constructed following the same procedure as for total employment.

Degree of openness. Real imports plus exports divided by real GDP from INE. Same procedures as for real GDP.

Index of globalization. This index measures economic globalization, including both actual flows (trade, foreign direct investment, portfolio investment, and income payments to foreigners) and restrictions (hidden import barriers, mean tariff rate, taxes on international trade, and capital account restrictions). Source: Swiss Institute for Business Cycle Research (globalization.kof.ethz.ch), see Dreher (2006). 


\section{References}

Ball, L., 2006. Has globalization changed inflation?, NBER Research working paper 12687.

Ball, L., Mankiw, N.G., Romer, D., 1988. The new Keynesian economics and the output-inflation trade-off. Brookings Papers on Economic Activity 1, 1-65.

Ball, L., Moffitt, R., 2001. Productivity growth and the Phillips curve. In: Krueger, A., Solow, R. (Eds.), The Roaring Nineties: Can Full Employment Be Sustained?. Russell Sage Foundation, New York.

Batini, N., Jackson, B., Nickell, S., 2005. An open economy new Phillips curve for the UK. Journal of Monetary Economics 52, 1061-1071

Bean, C., 2006. Globalisation and inflation. Bank of England Quarterly Bulletin Q4, 468-475.

Bentolila, S., Jimeno, J.F., 2006. Spanish unemployment: The end of the wild ride?. In: Martin Werding (Ed.), Structural Unemployment in Western Europe. Reasons and Remedies. MIT Press, Cambridge, MA, 317-343.

Bernanke, B.S., 2004. The Great Moderation. Speech given at the meetings of the Eastern Economic Association, Washington, DC, February 20.

Blanchard, O., Galí, J., 2007. Real wage rigidities and the new Keynesian model. Journal of Money, Credit, and Banking 39 (supplement), 35-66.

Borjas, G., 1999. The economic analysis of immigration. In: Ashenfelter, O., Card, D. (Eds.), Handbook of Labor Economics, vol. 3A, North Holland, Amsterdam, 1697-1760.

Borjas, G., 2003. The labor demand curve is downward sloping: Reexamining the impact of immigration on the labor market. Quarterly Journal of Economics 118, 1335-1370.

Brandt, N., Burniaux, J.-M., Duval, R., 2005. Assessing the OECD Jobs Strategy: Past development and reforms. OECD Economics Department working paper 429.

Calvo, G., 1983. Staggered prices in a utility maximizing framework. Journal of Monetary Economics 12, 383-398.

Card, D., 2001. Immigrants inflows, native outflows, and the local labor market impacts of higher immigration. Journal of Labor Economics 19, 22-64.

Carrasco, R., Jimeno, J.F., Ortega, C., 2008. The effect of immigration on the labor market performance of native-born workers: Some evidence for Spain. Journal of Population Economics 21, 627-648. 
Dolado, J., García-Serrano, C., Jimeno, J.F., 2002. Drawing lesson from the boom of temporary jobs in Spain. Economic Journal 112, 270-295.

Dolado, J., Vázquez, P., 2007. Los efectos económicos y las políticas de inmigración: Panorámica y reflexiones. In: Dolado, J., Vázquez, P. (Eds.), Ensayos sobre los Efectos Económicos de la Inmigración en España, Fundación de Estudios de Economía Aplicada, Madrid, 6-25.

Dreher, A., 2006. Does globalization affect growth? Evidence from a new index of globalization. Applied Economics 38, 1091-1110.

Engler, P., 2007. Gains from migration in a new-Keynesian framework. mimeo, Free University of Berlin.

Fabiani, S., Druant, M., Hernando, I., Kwapil, C., Landau, B., Loupias, C., Martins, F., Mathä, T., Sabbatini, R., Stahl, H. and Stokman, A., 2006. What firms' surveys tell us about price-setting behavior in the Euro area. International Journal of Central Banking 2, 3-47.

Fernández, C., Ortega, C., 2008. Labour market assimilation of immigrants in Spain: Employment at the expense of bad-job matches?. Spanish Economic Review 10, 83-107.

Galí, J., Gertler, M., 1999. Inflation dynamics: A structural econometric analysis. Journal of Monetary Economics 44, 195-222.

Galí, J., Gertler, M., López-Salido, J.D., 2001. European inflation dynamics"', European Economic Review 45, 1237-1279.

Galí, J., Gertler, M., López-Salido, J.D., 2003. Erratum to 'European inflation dynamics"', European Economic Review 47, 759-760.

Galí, J., López-Salido, J.D., 2001. A new Phillips curve for Spain. BIS Papers 3: Empirical Studies of Structural Changes and Inflation, Bank for International Settlements, Basel.

International Monetary Fund, 2006. How Has globalization affected inflation?. World Economic Outlook, Spring, 97-134.

Izquierdo, M., Regil, A.V., 2006. Actualización de las estimaciones de la tasa de desempleo estructural de la economía española. Boletín Económico 9, Banco de España, $55-62$.

Karanassou, M., Sala, H., Snower, D.J., 2007. Long-run inflation-unemployment dynamics: The Spanish Phillips curve and economic policy. Journal of Policy Modeling 30, 279-300.

Karanassou, M., Snower, D.J., 2007. Inflation persistence and the Phillips curve revisited. IZA discussion paper 2600. 
Kmenta, J., 1967. On estimation of the CES production function. International Economic Review 8, 180-189.

Lach, S., 2007. Immigration and prices. Journal of Political Economy 115, 548-587.

López-Salido, J.D., Restoy, F., Vallés, J., 2005. Inflation differentials in EMU: The Spanish case. Moneda y Crédito 220, 55-80.

Maravall, A., 2005. Tramo and Seats. Brief description of the programs. mimeo, Banco de España (www.bde.es/servicio/software/tramo/summprogs.pdf).

Nickell, S. J., M. Andrews, 1983. Unions, real wages and employment in Britain 195179. Oxford Economic Papers 35 (Supplement), 183-206.

Ottaviano, G., Peri, G., 2006. Rethinking the effects of immigration on wages. NBER working paper 12497.

Rabanal, P., 2006. Explaining inflation differentials between Spain and the Euro area. La Caixa working paper 2.

Razin, A., Binyamini, A., 2007. Flattened inflation-output tradeoff and enhanced antiinflation policy as an equilibrium outcome of globalization. HKIMR working paper 23.

Razin, A., Loungani, P., 2007. Globalization and equilibrium inflation-output tradeoffs. In: Frankel, J.A., Pissarides, C.A. (Eds.), NBER International Seminar on Macroeconomics 2005, National Bureau of Economic Research, Cambridge, MA.

Rogoff, K., 2003. Globalization and global disinflation. In: Federal Reserve Bank of Kansas City, Monetary Policy and Uncertainty: Adapting to a Changing Economy, 45-78.

Rotemberg, J., 1982. Sticky prices in the United States. Journal of Political Economy $90,1187-1211$.

Rotemberg, J., Woodford, M., 1999. The cyclical behavior of prices and costs. In: Taylor, J.B., Woodford, M. (Eds.), Handbook of Macroeconomics, Vol. 1B, North Holland, Amsterdam, 1051-1135. 
Table 1. Forward-looking and hybrid new Keynesian Phillips curves for Spain Dependent variable: Inflation rate

\begin{tabular}{lcccccc}
\hline & \multicolumn{2}{c}{$(1)$} & \multicolumn{2}{c}{$(2)$} & \multicolumn{2}{c}{$(3)$} \\
& \multicolumn{2}{c}{ FNPCI } & \multicolumn{2}{c}{ FNPCI } & \multicolumn{2}{c}{ HNPCI } \\
& Unrestricted & \multicolumn{2}{c}{ Restricted } & \multicolumn{2}{c}{ Unrestricted } \\
\cline { 2 - 7 } & Coeff. & $t$-ratio & Coeff. & $t$-ratio & Coeff. & $t$-ratio \\
\hline Future inflation rate & 0.493 & $(7.96)$ & 0.490 & $(11.34)$ & 0.615 & $(6.85)$ \\
Lagged inflation rate & 0.536 & $(11.35)$ & 0.510 & $(11.34)$ & 0.354 & $(4.35)$ \\
Twice-lagged inflation & & & & & 0.119 & $(2.41)$ \\
Unemployment rate rate & -0.116 & $(3.38)$ & -0.112 & $(3.49)$ & -0.109 & $(2.31)$ \\
Relative immigrant & & & & & & \\
$\quad$ unemployment rate & -0.100 & $(4.06)$ & -0.080 & $(3.19)$ & -0.145 & $(4.52)$ \\
Immigrant unemployment ratex & & & & & & \\
$\quad$ Immigration rate & -0.039 & $(3.52)$ & -0.031 & $(2.77)$ & -0.049 & $(3.09)$ \\
Immigrant unemployment rate $\times$ & & & & & & \\
$\quad$ Immigration rate squared & -0.005 & $(3.57)$ & -0.003 & $(2.66)$ & -0.008 & $(3.29)$ \\
$\Delta$ Real imported input prices & 0.004 & $(2.19)$ & 0.005 & $(2.77)$ & 0.005 & $(1.99)$ \\
& & & & & & \\
J-statistic ( $p$-value) & 0.144 & & 0.146 & & 0.130 & \\
Implied parameters: & & & & & & \\
$\beta$ & - & & 0.961 & $(11.42)$ & - & \\
$\theta$ & - & & 0.810 & $(15.76)$ & - & \\
$\rho$ & - & & 0.217 & $(7.62)$ & - & \\
$\nu$ & & & 0.706 & $(2.67)$ & & \\
\hline
\end{tabular}

Forward-looking (FNPCI) and Hybrid (HNPCI) NKPCs with immigration estimated by the Generalized Method of Moments. Period: 1982:1-2006:3. No. of observations: 99. $t$-ratios in parentheses. Instruments: a constant, four lags of the inflation rate, the relative unemployment rate of immigrants, the log share of immigrants in employment, the inflation rate of imported inputs, the labor income share, and two lags of cyclical output and of an index of the degree of globalization of the Spanish economy. See Appendix B for variable definitions. The implied parameters are estimated calibrating the following values for the remaining parameters: $\alpha=0.536, \chi=0.646$, and $\phi_{1}=1$ (see Appendix A.5). 
Table 2. Industry-specific forward-looking new Keynesian Phillips curve for Spain Dependent variable: Industry inflation rate

\begin{tabular}{|c|c|c|c|c|c|c|}
\hline & \multicolumn{2}{|c|}{$\begin{array}{c}(1) \\
\text { Manufacturing }\end{array}$} & \multicolumn{2}{|c|}{$\begin{array}{c}(2) \\
\text { Construction }\end{array}$} & \multicolumn{2}{|c|}{$\begin{array}{c}(3) \\
\text { Services }\end{array}$} \\
\hline & Coeff. & $t$-ratio & Coeff. & $t$-ratio & Coeff. & $t$-ratio \\
\hline Unemployment rate & -0.061 & $(2.18)$ & -0.102 & $(2.52)$ & -0.093 & $(2.08)$ \\
\hline $\begin{array}{l}\text { Relative immigrant } \\
\text { unemployment rate }\end{array}$ & -0.024 & $(1.03)$ & -0.042 & $(1.21)$ & -0.061 & $(2.32)$ \\
\hline $\begin{array}{l}\text { Immigrant unemployment rate } \times \\
\text { Immigration rate }\end{array}$ & 0.019 & $(0.61)$ & -0.017 & $(1.49)$ & -0.033 & $(2.36)$ \\
\hline $\begin{array}{l}\text { Immigrant unemployment rate } \times \\
\text { Immigration rate squared }\end{array}$ & 0.003 & $(1.10)$ & 0.002 & $(0.96)$ & -0.006 & $(1.82)$ \\
\hline$\Delta$ Real imported input prices & 0.005 & $(2.76)$ & 0.011 & $(1.86)$ & 0.008 & $(2.16)$ \\
\hline J-statistic ( $p$-value) & 0.130 & & 0.140 & & 0.150 & \\
\hline
\end{tabular}

Forward-Looking NKPC with immigration (FNPCI) estimated by the Generalized Method of Moments. Period: 1982:1-2006:3. No. of observations: 99. $t$-ratios in parentheses. Instruments: a constant, four lags of the inflation rate, the relative unemployment rate of immigrants, the log share of immigrants in employment, the inflation rate of imported inputs, the labor income share, and two lags of cyclical output and of an index of the degree of globalization of the Spanish economy. See Appendix B for variable definitions. The coefficients on future and lagged inflation rates are imposed to be 0.49 and 0.51 , respectively, so that $\beta=0.961$, as found in Table 1 . 


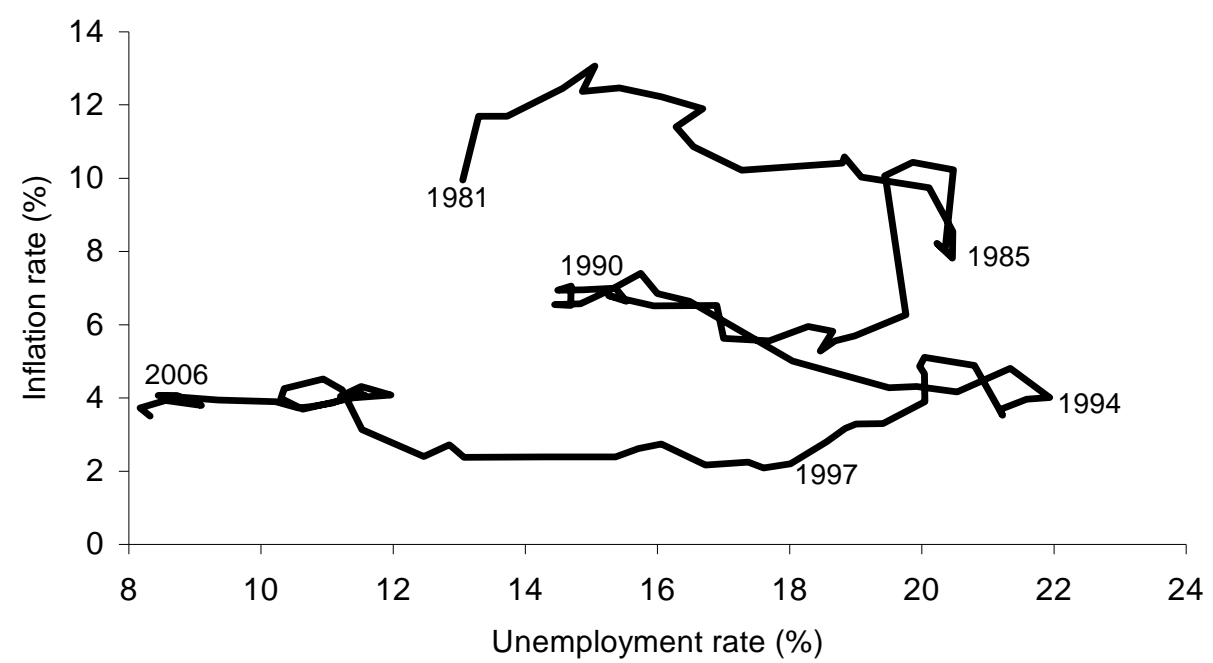

Figure 1: Inflation and unemployment in Spain, 1980-2006

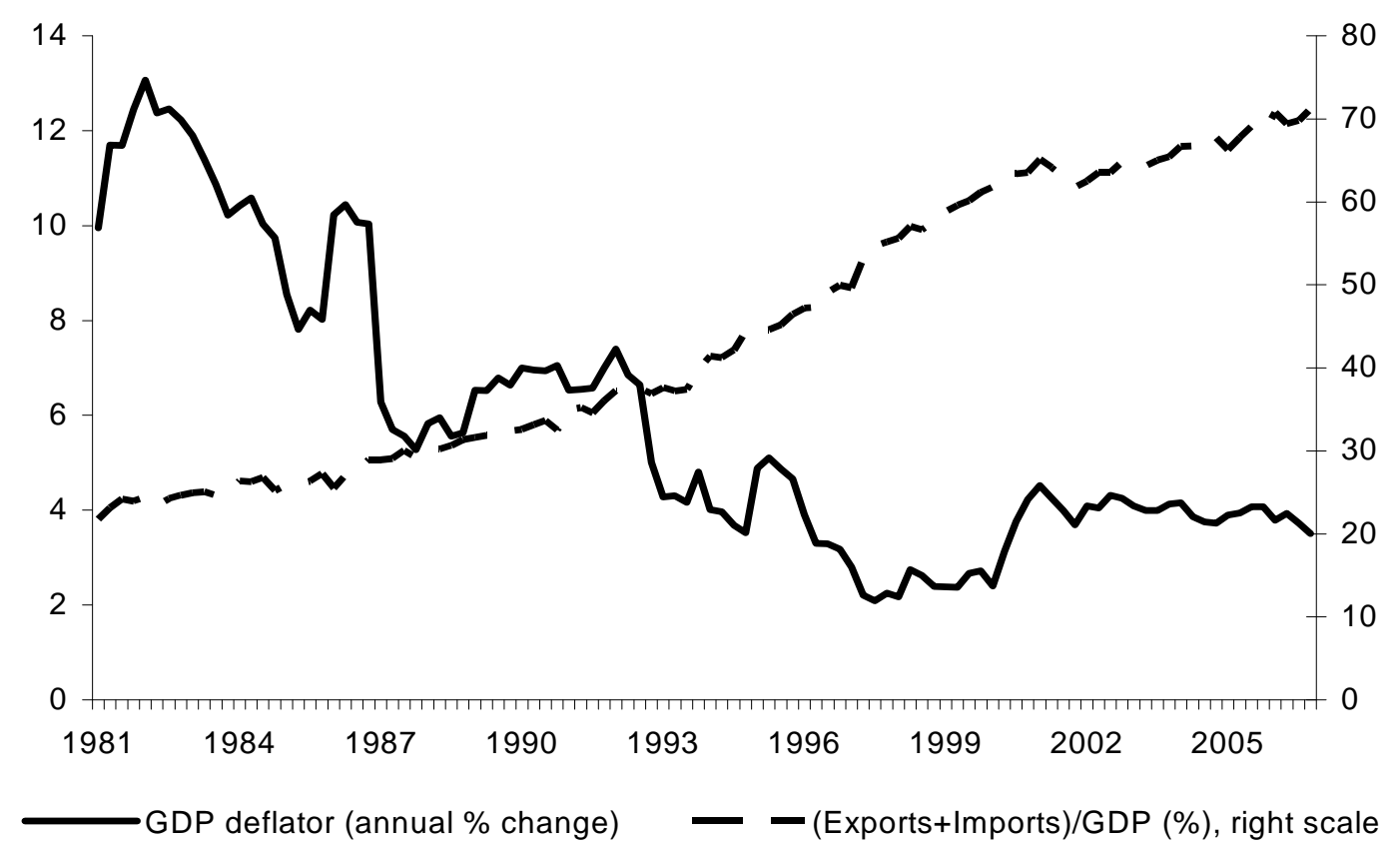

Figure 2: Inflation and the degree of openness in Spain, 1980-2006 


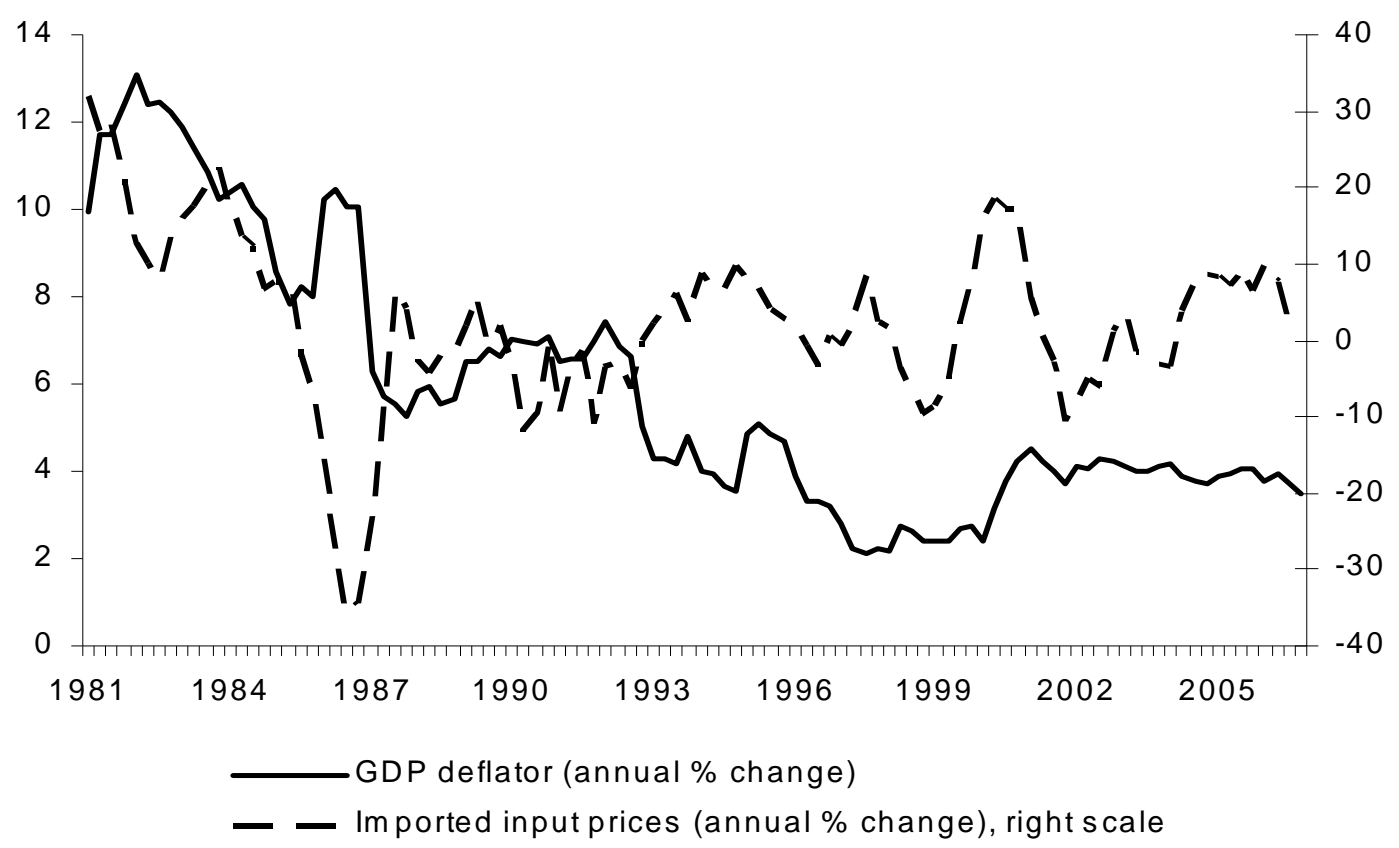

Figure 3: Inflation and the growth rate of imported input prices in Spain, 1980-2006

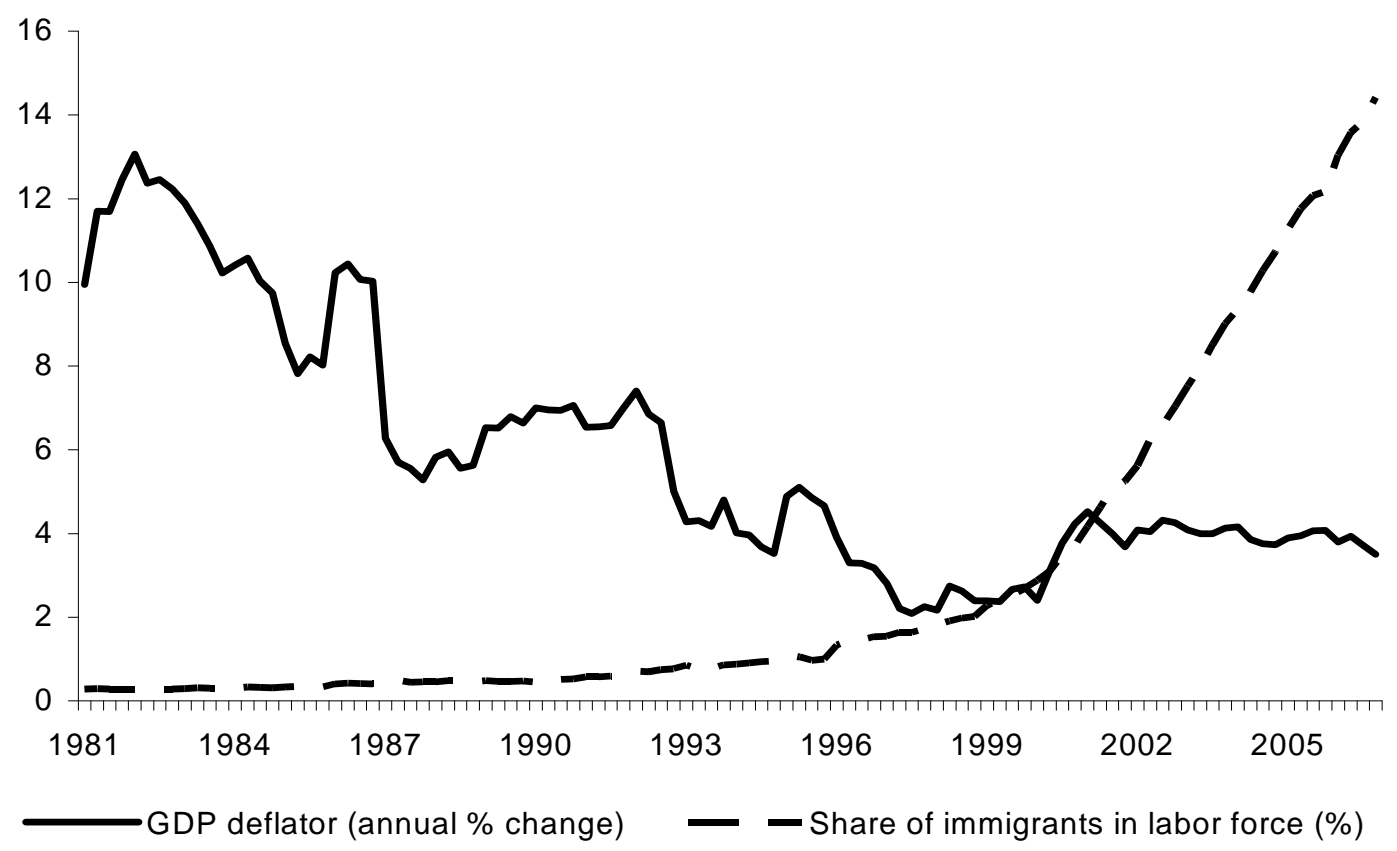

Figure 4: Inflation and the share of immigrants in the labor force in Spain, 1980-2006 


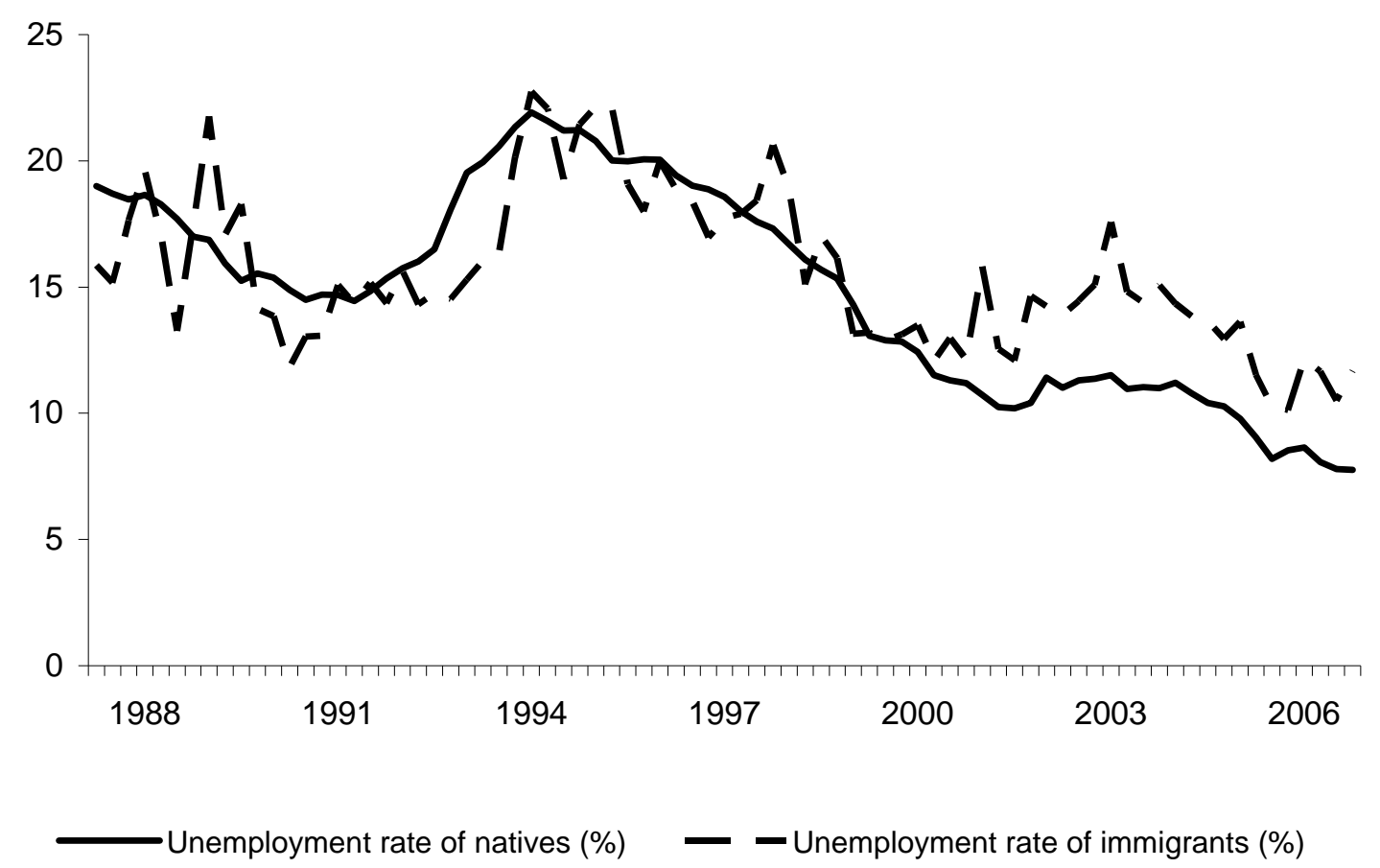

Figure 5: Unemployment rates of natives and immigrants in Spain, 1987-2006

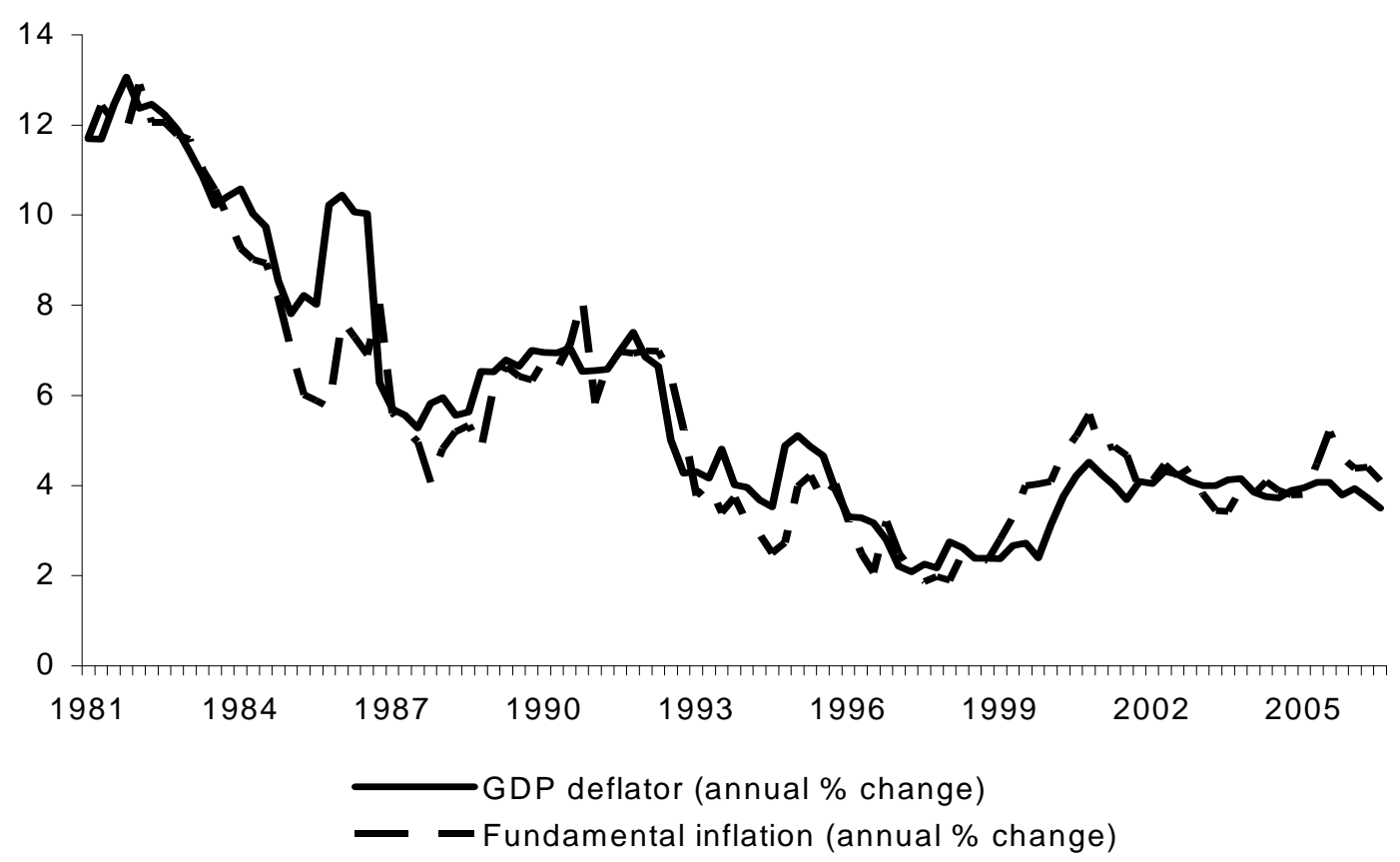

Figure 6: Actual and fundamental inflation in Spain, 1981-2006 